\title{
Resorcinarene Cavitand Polymers for the Remediation of Halomethanes and 1,4-Dioxane
}

Luke P. Skala, Anna Yang, Max J. Klemes, Leilei Xiao and William R. Dichtel*

Department of Chemistry, Northwestern University, 2145 Sheridan Road, Evanston, Illinois 60208, United States

Supplementary Information

\begin{tabular}{|c|}
\hline Correspondence Address \\
\hline Professor William R. Dichtel \\
Department of Chemistry \\
Northwestern University \\
2145 Sheridan Road \\
Evanston, IL 60208 (USA) \\
wdichtel@northwestern.edu \\
\hline
\end{tabular}

\section{Table of Contents}

A. Materials and Instrumentation $\quad$ S-2

B. Synthetic Procedures S-6

C. ${ }^{19}$ F MAS NMR Spectroscopy Studies $\quad$ S-12

$\begin{array}{lr}\text { D. Elemental Analysis } & \text { S-19 }\end{array}$

$\begin{array}{ll}\text { E. Thermogravimetric Analysis } & \text { S-20 }\end{array}$

$\begin{array}{ll}\text { F. Scanning Electron Microscopy } & \text { S-21 }\end{array}$

G. $\mathrm{CHCl}_{3}$ Removal Studies $\quad$ S-22

$\begin{array}{ll}\text { H. Dioxane Removal S-31 } & \text { S }\end{array}$

$\begin{array}{ll}\text { I. Standard Curves } & \text { S-33 }\end{array}$

J. ${ }^{1} \mathrm{H},{ }^{13} \mathrm{C}$ and ${ }^{19} \mathrm{~F}$ NMR Spectra $\quad$ S-37

$\begin{array}{lr}\text { K. Infrared Spectra } & \text { S-42 }\end{array}$

$\begin{array}{ll}\text { L. References } & \text { S-44 }\end{array}$ 


\section{A. Materials and Instrumentation.}

Materials: Reagents were purchased from Millipore-Sigma and used as received unless noted otherwise. Anhydrous DMSO was purchased through Millipore-Sigma (276855-1L) and dried over sieves. Fisher Chemical granular anhydrous potassium carbonate (173511) was used for all synthetic procedures. Activated carbon (Filtrasorb 600) was sourced from Calgon Carbon and received in granular form. The adsorbent was ground with a mortar and pestle and sieved to a particle size between $90-45 \mu \mathrm{m}$ to match the particle size of the resorcinarene polymers. Ambersorb 560 was sourced from Dow Chemical Company. The resin was used as received. 20 and $40 \mathrm{~mL}$ glass vials with open-cap PTFE septa were purchased from Chemglass Life Sciences (CG490401). 4 mL glass vials were purchased through Fisher Scientific (03-339-22B). These vials were used with screw caps with PTFE/Silicone septums purchased from Millipore-Sigma (SU860078). $20 \mathrm{~mL}$ headspace vials (27199) and PTFE/silicone crimp seals (27362) were purchased from Millipore-Sigma. 0.2 $\mu \mathrm{m}$ CHROMAFIL Xtra H-PTFE-20/13 (Hydrophilic PTFE) filters were purchased from Macherey-Nagel.

Critical Point Dryer: Supercritical $\mathrm{CO}_{2}$ activation was performed on a Leica EM CPD 300. Samples were stored in tea bags for both Soxhlet extraction and critical point drying. Immediately following Soxhlet extraction with methanol, the samples were transferred to the drying chamber without fully removing residual methanol. The drying chamber was cooled to $15^{\circ} \mathrm{C}$ and filled with $\mathrm{CO}_{2}$ at the "fast" setting rate. A delay of 120 seconds was used with an exchange speed of " 5 " and 45 cycles of $\mathrm{CO}_{2}$ exchange. The samples were then cooled to $40{ }^{\circ} \mathrm{C}$ on the "slow" setting and the pressure was also relieved on the "slow 20\%" setting. 
Solid-State ${ }^{19}$ F MAS NMR Spectroscopy: Solid-state ${ }^{19}$ F NMR spectroscopy was performed on a Bruker Avance $600 \mathrm{MHz}$ NMR spectrometer using a Bruker HX $1.3 \mathrm{~mm}$ MAS probe, in which the ${ }^{1} \mathrm{H}$ channel was tuned to ${ }^{19} \mathrm{~F}$. The sample spinning rate was controlled by a Bruker pneumatic MAS unit at $48 \mathrm{kHz}$. The ${ }^{19} \mathrm{~F} 90^{\circ}$ pulse length was used and in all ${ }^{19} \mathrm{~F}$ experiments, 2048 scans were collected for each sample. Flufenamic acid was used as an external standard, and its ${ }^{19} \mathrm{~F}$ resonance was set to $-61.5 \mathrm{ppm} .^{1}$

Solution ${ }^{19}$ F NMR Spectroscopy: 3-(trifluoromethyl)benzonitrile (-61.75 ppm) was used to reference the fluorine peak shifts for $\mathbf{S 1}$ and $\mathbf{S 2}$, as well as for analyzing model reactions involving these compounds. The peak shift of 3-(trifluoromethyl)benzonitrile was determined via comparison to Flufenamic acid.

Solution Nuclear Magnetic Resonance Spectroscopy: Both ${ }^{1} \mathrm{H}$ and ${ }^{13} \mathrm{C}$ NMR spectra were obtained on a Bruker Avance III $500 \mathrm{MHz}$ equipped with a DHC CryoProbe. ${ }^{19} \mathrm{~F}$ NMR spectra were obtained on an Agilent $500 \mathrm{MHz}$ DD2 spectrometer.

Solid State ${ }^{13} \mathrm{C}$ Cross Polarization Magic Angle Spinning (CP-MAS) NMR Spectroscopy: Spectra were taken on a Varian $400 \mathrm{MHz}$ with a spinning rate of $15 \mathrm{KHz}$. The spectra were referenced using adamantane as an external standard.

Surface Area Analysis was performed on a Micromeritics ASAP 2420 Accelerated Surface Area and Porosity Analyzer. At least $25 \mathrm{mg}$ of polymer was used for each analysis. The sample was degassed at $40{ }^{\circ} \mathrm{C}$ until the offgas rate was less than $1.0 \mu \mathrm{mHg} / \mathrm{min}$. Isotherms were performed using ultrahigh purity $\mathrm{N}_{2}$ at $77 \mathrm{~K}$. Brunauer-Emmett-Teller surface areas $\left(S_{\mathrm{BET}}\right)$ were calculated using the linear region $\left(P / P_{0}\right.$ of $\left.0.05-0.1\right)$ of the isotherm.

Infrared Spectroscopy was performed on a Nicolet iS10 FT-IR with a Diamond ATR. 
Thermogravimetric Analysis: Thermal stability was assessed on a Netzsch's Simultaneous Thermal Analysis coupled to a GC-MS under a He atmosphere. Approximately $5 \mathrm{mg}$ of polymer was used for each analysis. A temperature range of $20-800^{\circ} \mathrm{C}$ and $10^{\circ} \mathrm{C} / \mathrm{min}$ ramp rate were used.

Scanning Electron Microscopy: Polymer powders were attached to aluminum sample holders with double sided carbon tape. Samples were coated with 6nm of Osmium and imaged with a FEI Quanta 650 ESEM. Images were collected using a large field detector in low vacuum mode at an accelerating voltage of $25 \mathrm{kHz}$.

Gas Chromatography Mass Spectroscopy (GC-MS) was performed on an Agilent 6890N GC system with an Agilent 5973 mass selective detector. Samples were injected using an Agilent 7697A headspace sampler. For each measurement, $2 \mathrm{~mL}$ of a liquid sample was loaded into a 20 $\mathrm{mL}$ vial, which was crimp sealed with a silicone cap. The sample was incubated in a headspace sampler for 7 minutes at $80{ }^{\circ} \mathrm{C}$. While being incubated the samples were shaken $\left(71 \mathrm{~min}^{-1}\right)$. The vapor phase $(0.2 \mathrm{~mL})$ was injected into the GC-MS with a split ratio of 20:1. The headspace loop and transfer line were set to $90{ }^{\circ} \mathrm{C}$ and $100{ }^{\circ} \mathrm{C}$ respectively. The oven temperature was held at 45 ${ }^{\circ} \mathrm{C}$ for 3 min and heated to $200{ }^{\circ} \mathrm{C}\left(40{ }^{\circ} \mathrm{C} / \mathrm{min}\right)$ and held for 1 minute. An ion extraction was performed on the chromatogram using the most abundant ion of the analyte of interest (see table below). The relevant peak was integrated to obtain a value for the residual analyte concentration. Standard curves were constructed with each analyte to determine the linear concentration regime and detection limit (see standard curves below). 


\begin{tabular}{ccc} 
Halomethane & $\begin{array}{c}\text { Retention Time } \\
\text { (minutes) }\end{array}$ & Ion Used (Da) \\
\hline $\mathrm{CH}_{2} \mathrm{Cl}_{2}$ & 2.271 & 84 \\
$\mathrm{CHCl}_{3}$ & 3.223 & 83 \\
$\mathrm{CCl}_{4}$ & 1.930 & 117 \\
$\mathrm{CHBrCl}_{2}$ & 4.588 & 83 \\
\hline $\mathrm{CHBr}_{2} \mathrm{Cl}$ & 5.65 & 129 \\
\hline $\mathrm{CHBr}_{3}$ & 6.465 & 173 \\
\hline
\end{tabular}

Table S1. Retention time of halomethane pollutants and ions used for their quantification.

Electrospray Ionization - Mass Spectroscopy (ESI-MS): Detection of phenoxy-substituted products $\mathbf{S 3}$ and $\mathbf{S 4}$ were conducted using Bruker ESI-ion trap mass spectrometer (Amazon SL). The mobile phase consisted of $\mathrm{CH}_{3} \mathrm{OH}$ and $\mathrm{CH}_{2} \mathrm{Cl}_{2}$. Samples were injected at $1 \mu \mathrm{L}$ volumes directly to the mass spectrometer with a loading pump delivering $200 \mu \mathrm{L} \mathrm{min}{ }^{-1}$ of a mobile phase consisting of $50 \% \mathrm{CH}_{2} \mathrm{Cl}_{2}$. The mass spectrometer was operated with electrospray ionization in alternating polarity mode. The mass range sampled was from 50 to $2200 \mathrm{~m} / \mathrm{z}$. 


\section{B. Synthetic Procedures}
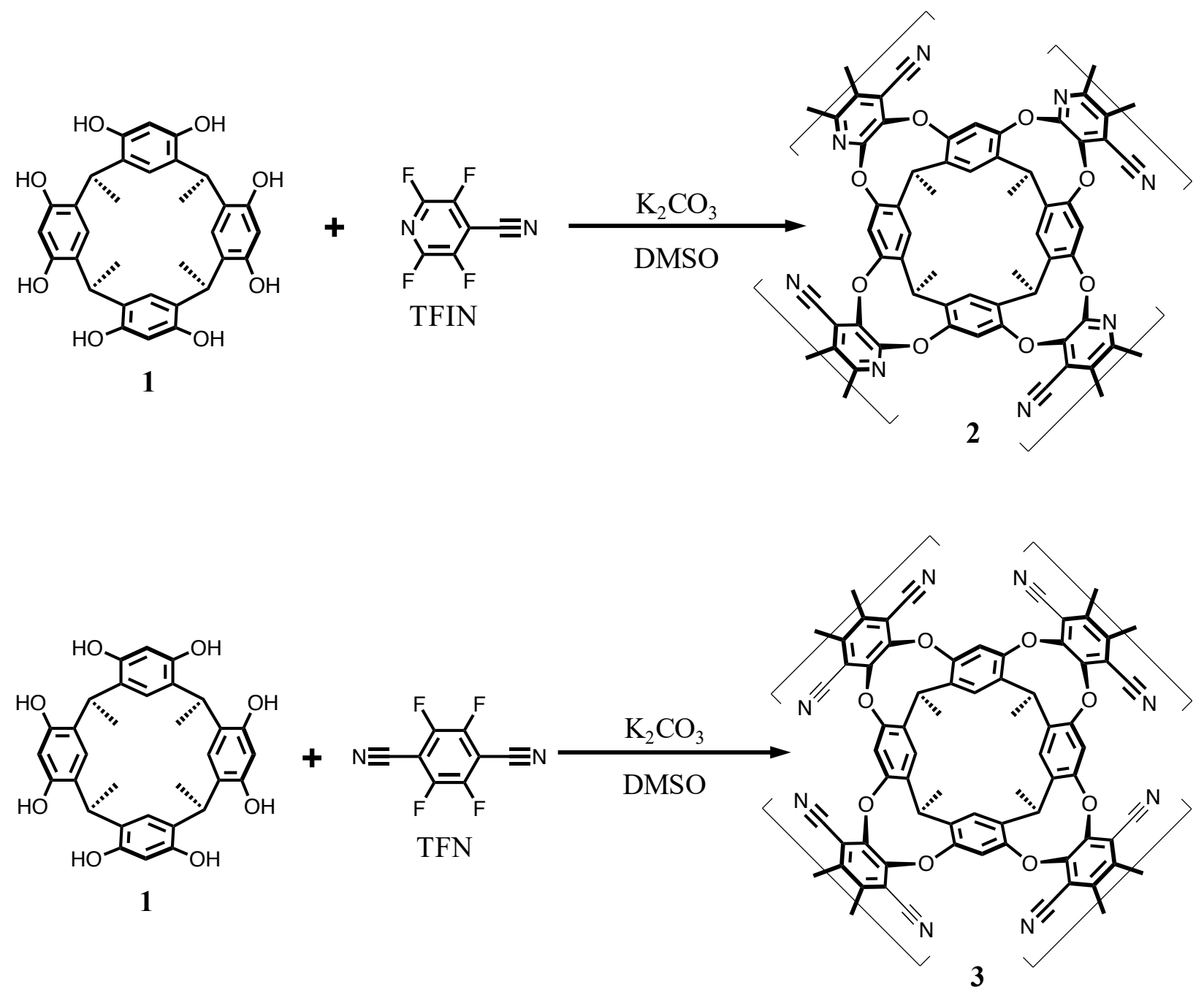

General Polymerization Procedure: Resorcinarene (1, $125 \mathrm{mg}, 0.230 \mathrm{mmol})$ and TFIN (81 mg, $0.46 \mathrm{mmol}$ ) or TFN (91 mg, $0.46 \mathrm{mmol})$ were added to a $20 \mathrm{~mL}$ reaction vial. Anhydrous DMSO (4 mL) was added using a syringe. The vial was heated to dissolve the monomers. After the monomers were fully dissolved, $\mathrm{K}_{2} \mathrm{CO}_{3}(636 \mathrm{mg}, 4.60 \mathrm{mmol})$ was added and the reaction was immediately placed on a heating block preheated to $150^{\circ} \mathrm{C}$. The reaction mixture was heated at $150{ }^{\circ} \mathrm{C}$ for 3 hours and gelled within 5 minutes. The surface temperature of the heating block was measured with an IR thermometer to be $\sim 162^{\circ} \mathrm{C}$. Following 3 hours of heating the reaction was 
cooled to RT. Nanopure $\mathrm{H}_{2} \mathrm{O}$ was added to the sample, and the gel was pulverized with a spatula. The pulverized gel was then filtered and placed into $50 \mathrm{~mL}$ of nanopure $\mathrm{H}_{2} \mathrm{O}$. A solution of $\mathrm{HCl}$ (1 M) was slowly added until a $\mathrm{pH}$ of 1-3 was reached. The solution was then stirred for an additional 10 minutes. The polymer was stirred in acetone $(100 \mathrm{~mL})$ for 45 minutes. The polymer was continuously washed with hot $\mathrm{MeOH}$ in a Soxhlet extractor, after which it was activated using supercritical $\mathrm{CO}_{2}$. The isolated polymers were grinded into a powder using a mortar and pestle and sieved to a particle size of $90-45 \mu \mathrm{m}$ to match that of the activated carbon benchmarks. The resulting polymers were isolated in $93 \%$ and $97 \%$ yield for $\mathbf{2}$ and $\mathbf{3}$, respectively. Theoretical yields were based on the initial masses of the monomers and corrected based on their combustion analysis to account for the residual fluorine content.

\begin{tabular}{|c|c|c|c|c|c|c|c|c|c|c|}
\hline \multirow[b]{2}{*}{ Polymer } & \multicolumn{4}{|c|}{ Reaction Conditions } & \multicolumn{3}{|c|}{ Elemental analysis } & \multicolumn{3}{|c|}{ Removal Study } \\
\hline & $\begin{array}{c}{[\text { Resorcinarene] }} \\
(\mathrm{mmol})\end{array}$ & $\begin{array}{c}\text { [TFIN or TFN] } \\
(\mathrm{mmol})\end{array}$ & $\begin{array}{l}\text { Reaction } \\
\text { Temp }\left({ }^{\circ} \mathrm{C}\right)\end{array}$ & $\begin{array}{l}{\left[\mathrm{K}_{2} \mathrm{CO}_{3}\right]} \\
(\mathrm{M})\end{array}$ & $\mathbf{F} \%$ & N\% & $\begin{array}{l}\text { Flourine Per } \\
\text { Linker }\end{array}$ & $\begin{array}{c}{\left[\mathrm{CHCl}_{3}\right]} \\
(\mu \mathrm{g} / \mathrm{L})\end{array}$ & $\begin{array}{c}\text { [Absorbant] } \\
\text { (mg/L) }\end{array}$ & $\begin{array}{c}\mathrm{CHCl}_{3} \text { removal } \\
(\%)\end{array}$ \\
\hline 2 & 57.5 & 115 & 75 & 1.15 & N/A & N/A & N/A & 100 & 30 & 74.3 \\
\hline 2 & 57.5 & 115 & 75 & 0.46 & N/A & N/A & N/A & 100 & 30 & 67.6 \\
\hline 2 & 57.5 & 115 & 75 & 0.23 & N/A & N/A & $\mathrm{N} / \mathrm{A}$ & 100 & 30 & 68.9 \\
\hline 2 & 57.5 & 115 & 75 & 1.15 & 4.09 & 7.02 & 0.9 & 100 & 50 & 80.3 \\
\hline 2 & 57.5 & 115 & 150 & 1.15 & 3.45 & 6.95 & 0.7 & 100 & 50 & 87.2 \\
\hline 2 & 38.3 & 77 & 150 & 0.77 & & & No Polymer Isolated & & & \\
\hline 2 & 57.5 & 115 & 150 & 1.15 & 3.45 & 6.95 & 0.7 & 100 & 30 & 85.2 \\
\hline 2 & 115 & 230 & 150 & 2.3 & N/A & N/A & N/A & 100 & 30 & 64.8 \\
\hline 3 & 57.5 & 115 & 75 & 1.15 & 5.26 & 6.34 & 1.2 & 100 & 300 & 55 \\
\hline 3 & 57.5 & 115 & 120 & 1.15 & 3.94 & 6.33 & 0.9 & 100 & 300 & 78.7 \\
\hline 3 & 57.5 & 115 & 150 & 1.15 & 3.19 & 6.43 & 0.7 & 100 & 300 & 86.2 \\
\hline
\end{tabular}

Table S2. Optimization of the polymerization procedure based on minimizing residual fluorine content and maximizing $\mathrm{CHCl}_{3}$ adsorption. 


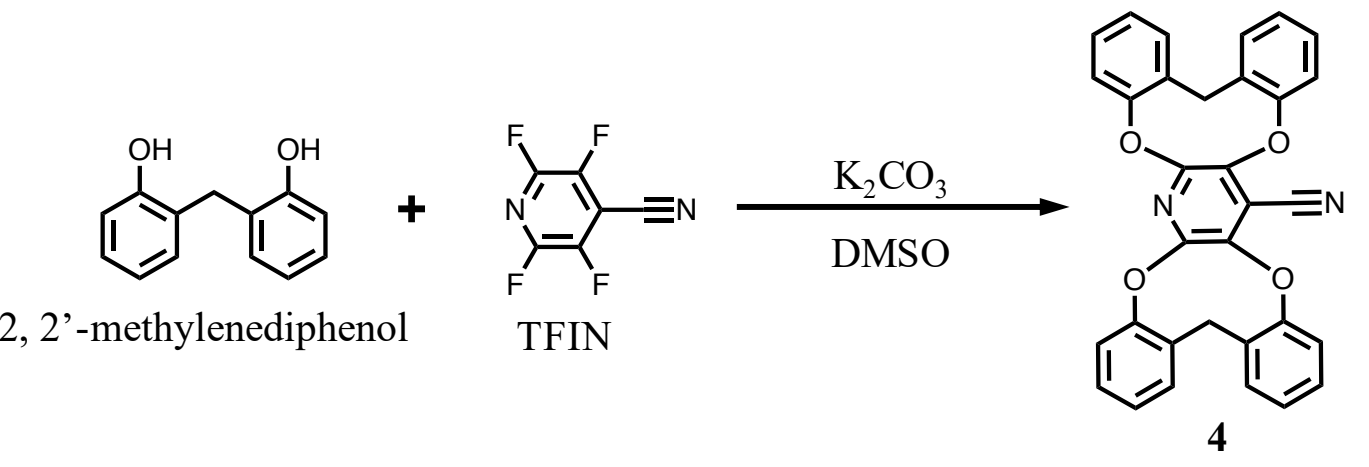

Synthesis of Model Compound 4: 2,2'-methylenediphenol (184 mg, $0.92 \mathrm{mmol})$ and TFIN (81 $\mathrm{mg}, 0.46 \mathrm{mmol}$ ) were added to a $20 \mathrm{~mL}$ reaction vial. Anhydrous DMSO (4 mL) was added using a syringe. The vial was heated to dissolve the $2,2^{\prime}$-methylenediphenol. When the monomers were fully dissolved, $\mathrm{K}_{2} \mathrm{CO}_{3}(127 \mathrm{mg}, 0.92 \mathrm{mmol})$ was added. The solution was then heated at $150{ }^{\circ} \mathrm{C}$ for 25 minutes and monitored via TLC $\left(\mathrm{SiO}_{2}, 40: 60\right.$ hexanes:DCM). The reaction solution was cooled to room temperature and then added to an excess of brine, and the resulting precipitate was recovered by filtration. The recovered solids were dissolved in DCM and purified using column chromatography (silica, 40:60 hexanes:DCM). The product was then dried under vacuum at 100 ${ }^{\circ} \mathrm{C}$ to provide 4 (77 mg, 34\% yield). 4: ${ }^{1} \mathrm{H}$ NMR (500 MHz, $\left.\mathrm{CD}_{2} \mathrm{Cl}_{2}\right): \delta 7.31-7.25(\mathrm{~m}, 6 \mathrm{H}), 7.23-$ $7.21(\mathrm{~m}, 4 \mathrm{H}), 7.19-7.14(\mathrm{~m}, 6 \mathrm{H}), 3.97(\mathrm{~s}, 4 \mathrm{H}){ }^{13} \mathrm{C} \mathrm{NMR}\left(126 \mathrm{MHz}, \mathrm{CD}_{2} \mathrm{Cl}_{2}\right) \delta 154.81,154.36$, $144.34,143.92,133.97,131.67,131.37,130.65,128.67,128.50,126.45,124.03,120.97,111.92$, 107.39, 33.16 ppm. HRMS (ESI) calcd for $\mathrm{C}_{32} \mathrm{H}_{20} \mathrm{~N}_{2} \mathrm{O}_{4}\left[\mathrm{M}^{*}\right]^{+} 496.1423$, found 496.1425. 


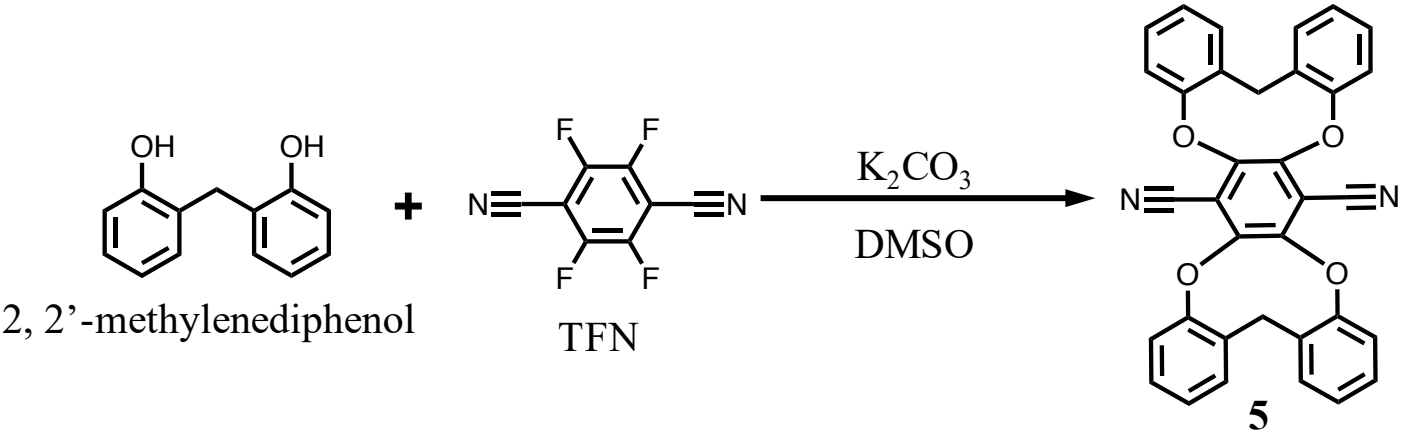

Synthesis of Model Compound 5: 2,2'-methylenediphenol (184 mg, $0.92 \mathrm{mmol}$ ) and TFN (91 $\mathrm{mg}, 0.46 \mathrm{mmol}$ ) was added to a $20 \mathrm{~mL}$ reaction vial. $4 \mathrm{~mL}$ of anhydrous DMSO was added using a syringe. The vial was heated to dissolve the $2,2^{\prime}$-methylenediphenol. When the monomers were fully dissolved, $\mathrm{K}_{2} \mathrm{CO}_{3}(127 \mathrm{mg}, 0.92 \mathrm{mmol})$ was added. The solution was then heated at $150{ }^{\circ} \mathrm{C}$ for 25 minutes and monitored via TLC ( $\mathrm{SiO}_{2}, 20: 80$ hexanes:DCM). The reaction solution was cooled to room temperature and then added to an excess of brine, and the resulting precipitate was recovered by filtration. The recovered solids were dissolved in DCM and purified using column chromatography $\left(\mathrm{SiO}_{2}, 20: 80\right.$ hexanes:DCM). The product was then dried under vacuum at 100 ${ }^{\circ} \mathrm{C}$ to provide $5\left(55 \mathrm{mg}, 23 \%\right.$ yield). 5: ${ }^{1} \mathrm{H}$ NMR (500 MHz, $\left.\mathrm{CD}_{2} \mathrm{Cl}_{2}\right): \delta 7.28(\mathrm{ddd}, J=9.05,7.28$, $1.72 \mathrm{~Hz}, 6 \mathrm{H}), 7.24$ (dd, $J=6.98,1.68 \mathrm{~Hz}, 6 \mathrm{H}), 7.17$ (ddd, $J=8.23,6.98,1.29 \mathrm{~Hz} 4 \mathrm{H}), 4.09$ (s, 4H) ${ }^{13} \mathrm{C}$ NMR $\left(126 \mathrm{MHz}, \mathrm{CDCl}_{3}\right) \delta 154.44,147.62,130.91,130.69,128.25,126.11,122.23$, 112.12, 107.27, 33.78 ppm. Elemental Analysis: calcd for $\mathrm{C}_{34} \mathrm{H}_{20} \mathrm{~N}_{2} \mathrm{O}_{4} \mathrm{C}, 78.45 ; \mathrm{H}, 3.87 ; \mathrm{N}, 5.38$ found C, 78.39; H, 3.60; N, 5.32. 


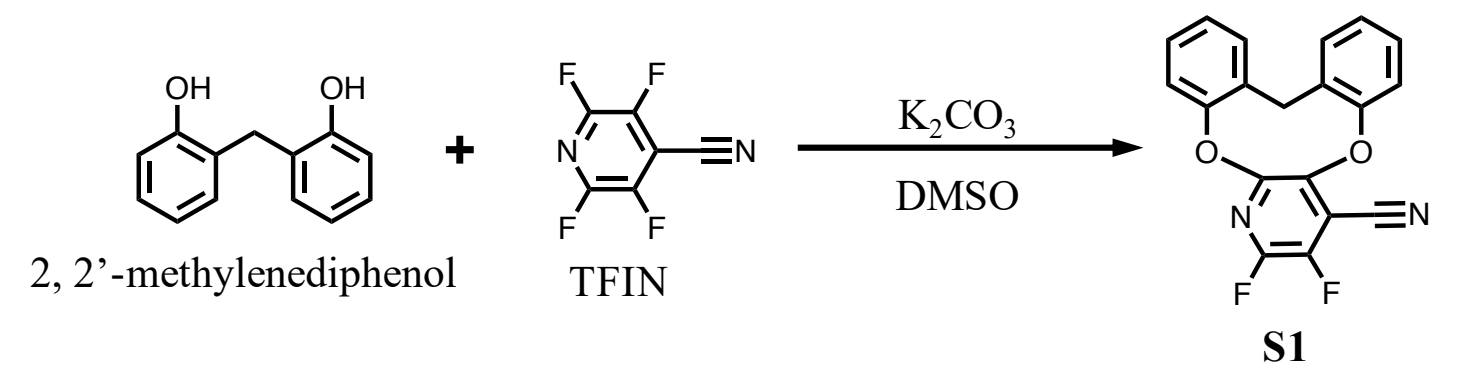

Synthesis of S1: 2,2'-methylenediphenol (184 mg, $0.92 \mathrm{mmol})$ and TFIN (162 mg, $0.92 \mathrm{mmol}$ ) was added to a $20 \mathrm{~mL}$ reaction vial. Anhydrous DMSO $(8 \mathrm{~mL})$ was added using a syringe. The vial was heated to dissolve the $2,2^{\prime}$-methylenediphenol. When the monomers were fully dissolved, $\mathrm{K}_{2} \mathrm{CO}_{3}(127 \mathrm{mg}, 0.92 \mathrm{mmol})$ was added. The solution was then heated at $150{ }^{\circ} \mathrm{C}$ for 5 minutes, and reaction times longer than 10 minutes provided diminished yields. The reaction was monitored via TLC $\left(\mathrm{SiO}_{2}, 50: 50\right.$ hexanes:DCM). The reaction solution was cooled to room temperature and then added to an excess of brine, and the resulting precipitate was recovered by filtration. The recovered solids were dissolved in DCM and purified using column chromatography $\left(\mathrm{SiO}_{2}, 50: 50\right.$ hexanes:DCM). The product was then dried under vacuum at $100{ }^{\circ} \mathrm{C}$ to provide $\mathbf{S 1}(50 \mathrm{mg}, 16 \%$ yield). S1: ${ }^{1} \mathrm{H}$ NMR (500 MHz, DMSO): $\delta 7.47$ (dd, $\left.J=7.54,1 \mathrm{H}\right), 7.33-7.29(\mathrm{~m}, 3 \mathrm{H}), 7.26-7.21$ (m, 2H), 7.21-7.16 (m, 2H), $3.96(\mathrm{~s}, 2 \mathrm{H}){ }^{13} \mathrm{C}$ NMR (126 MHz, DMSO) $\delta 153.58,152.78,143.03$ (dd, $J=265.82,31.56 \mathrm{~Hz}), 142.91(\mathrm{~d}, J=6.14 \mathrm{~Hz}), 142.29$ (dd, $J=3.48,11.11 \mathrm{~Hz}), 142.27$ (dd, $J=14.32,236.69 \mathrm{~Hz}), 133.69,131.60,130.71,130.10,128.52,128.25,126.46,126.13,123.00$, 119.99, $109.40(\mathrm{~d}, J=4.02 \mathrm{~Hz}), 106.11(\mathrm{dd}, J=13.89,4.19 \mathrm{~Hz}), 31.43{ }^{19} \mathrm{~F}$ NMR $(376 \mathrm{MHz}$, DMSO) $\delta-91.91(\mathrm{~d}, J=24.97 \mathrm{~Hz}),-136.39(\mathrm{~d}, J=24.93 \mathrm{~Hz}) \mathrm{ppm}$. HRMS (ESI) calcd for $\mathrm{C}_{19} \mathrm{H}_{11} \mathrm{~F}_{2} \mathrm{~N}_{2} \mathrm{O}_{2}[\mathrm{M}+\mathrm{H}]^{+}$337.0788, found 337.0774. 


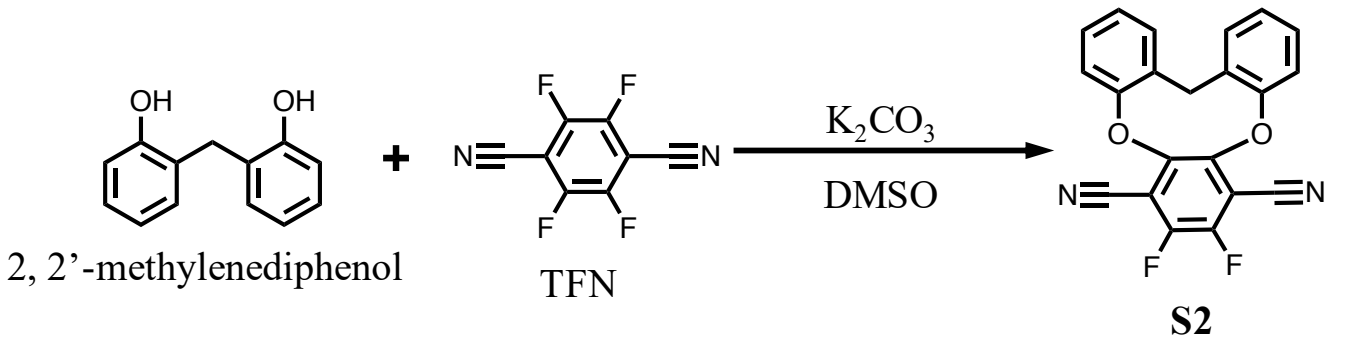

Synthesis of S2: 2,2'-methylenediphenol (92 mg, $0.46 \mathrm{mmol})$ and TFN (91 mg, $0.46 \mathrm{mmol})$ was added to a $20 \mathrm{~mL}$ reaction vial. Anhydrous DMSO (4 mL) was then added to the reaction vial using a syringe. The vial was heated to dissolve the $2,2^{\prime}-$ methylenediphenol. When the monomers were fully dissolved, $\mathrm{K}_{2} \mathrm{CO}_{3}(64 \mathrm{mg}, 0.46 \mathrm{mmol})$ was added. The solution was then heated at 150 ${ }^{\circ} \mathrm{C}$ for 5 minutes. Running the reaction longer than 10 minutes resulted in diminished yields. This reaction was monitored via TLC ( $\mathrm{SiO}_{2}, 80: 20$ hexanes:ethyl acetate). The reaction solution was cooled to room temperature and then added to an excess of brine, and the resulting precipitate was recovered by filtration. The recovered solids were dissolved in DCM and purified using column chromatography $\left(\mathrm{SiO}_{2}, 80: 20\right.$ hexanes:ethyl acetate). The product was then dried under vacuum at $100{ }^{\circ} \mathrm{C}$ to provide $\mathbf{S 1}$ (34 mg, 20\% yield). S1: ${ }^{1} \mathrm{H}$ NMR (500 MHz, DMSO): $\delta$ 7.35-7.32 (m, 2H), 7.31-7.27 (m, 4H), 7.23-7.20 (m, 2H), $4.09(\mathrm{~s}, 2 \mathrm{H}){ }^{13} \mathrm{C}$ NMR (126 MHz, DMSO) $\delta 153.54,147.26$ $(\mathrm{dd}, J=259.73,15.73 \mathrm{~Hz}), 146.16(\mathrm{~d}, J=2.81 \mathrm{~Hz}), 131.63,130.59,128.33,126.38,121.65$, 109.64, $102.51(\mathrm{dd}, J=10.54,7.06 \mathrm{~Hz}), 32.16{ }^{19} \mathrm{~F}$ NMR (470 MHz, DMSO) $\delta-132.72 \mathrm{ppm}$. 


\section{C. ${ }^{19}$ F MAS NMR Spectroscopy Studies}

\section{Model Reaction for ${ }^{19}$ F MAS Solid State Spectroscopy:}

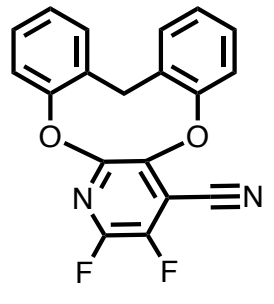

S1

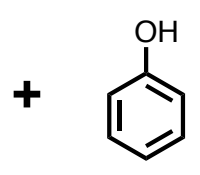

Phenol

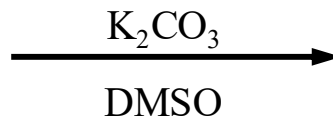

DMSO

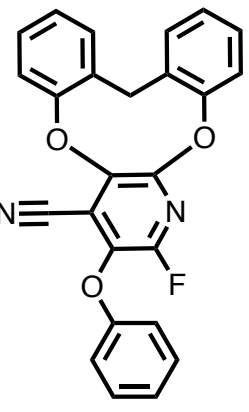

S3

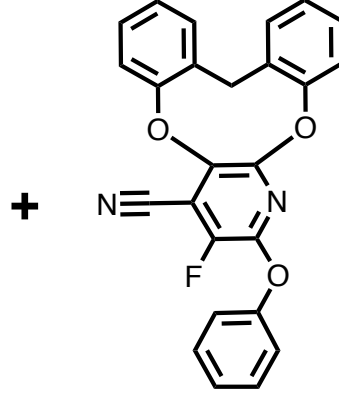

S4

A 1:1 ratio of $\mathbf{S 1}(17 \mathrm{mg}, 0.05 \mathrm{mmol})$ and phenol $(4.7 \mathrm{mg}, 0.05 \mathrm{mmol}))$ was added to a $4 \mathrm{~mL}$ reaction vial. Anhydrous DMSO (1 $\mathrm{mL})$ was then added using a syringe. 3(trifluoromethyl)benzonitrile $(2 \mu \mathrm{L})$ was added to the reaction and used as an internal standard. The vial was heated to dissolve $\mathbf{S 1}$ and phenol. When the monomers were fully dissolved, $6.9 \mathrm{mg}$ of $\mathrm{K}_{2} \mathrm{CO}_{3}(6.9 \mathrm{mg}, 0.05 \mathrm{mmol})$ was added to the reaction vial. The reaction was then heated at 150 ${ }^{\circ} \mathrm{C}$ for 25 minutes. Aliquots of $100 \mu \mathrm{L}$ of the reaction were taken prior to adding $\mathrm{K}_{2} \mathrm{CO}_{3}$, as well as 5,15 , and 25 minutes after base addition. These aliquots were centrifuged, added to $0.5 \mathrm{~mL}$ of DMSO, and analyzed by solution ${ }^{19} \mathrm{~F}$ NMR spectroscopy. The spectra exhibited two new singlets: one at $-84.67 \mathrm{ppm}$, corresponding to substitution adjacent to the nitrile (S3), and the other at 133.25 ppm, corresponding to substitution adjacent to pyridine (S4). This model reaction exhibited a 7:1 preference for $\mathbf{S 3}$ relative to $\mathbf{S 4}$. This finding suggests that the position adjacent to the nitrile is more electrophilic, presumably due to electron withdrawing of the nitrile substituent. The formation of $\mathbf{S 3}$ and $\mathbf{S 4}$ was also confirmed by ESI-MS. 
${ }^{19}$ F NMR of Crude Model Reaction:

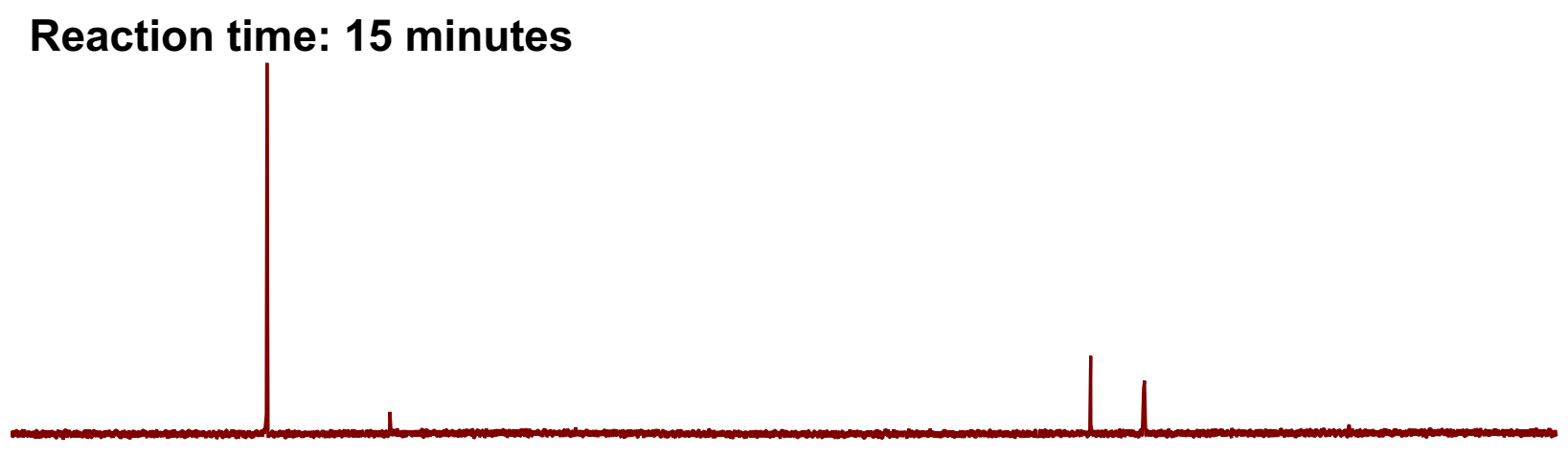

Reaction time: 0 minutes
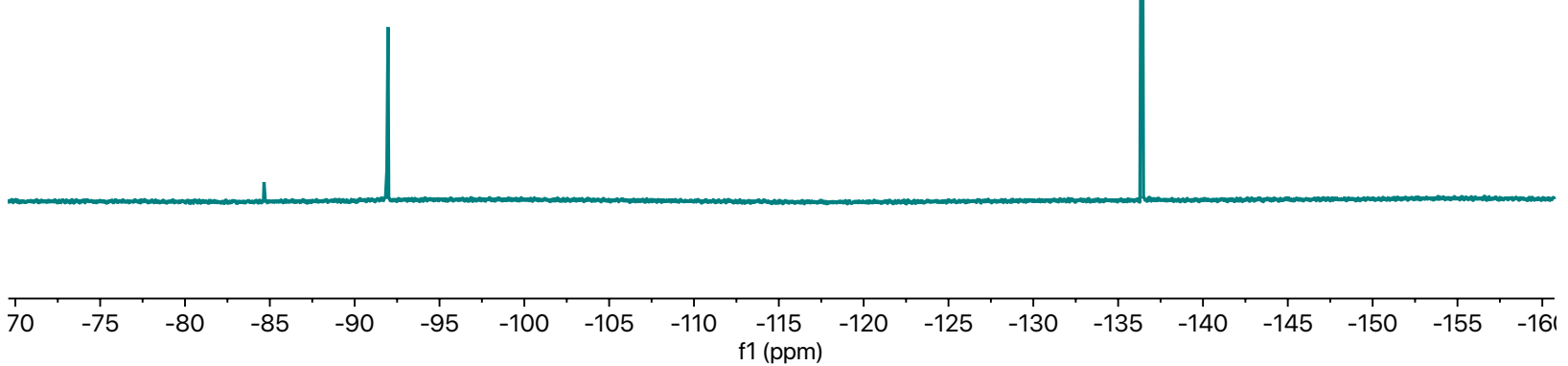

Figure S1. Partial ${ }^{19}$ F NMR spectra of S1 (bottom) and after reacting with phenol for 15 minutes (top). 
Electrospray Ionization Mass Spectroscopy (ESI-MS) for Confirmation of S3 and S4 in the Model Reaction:

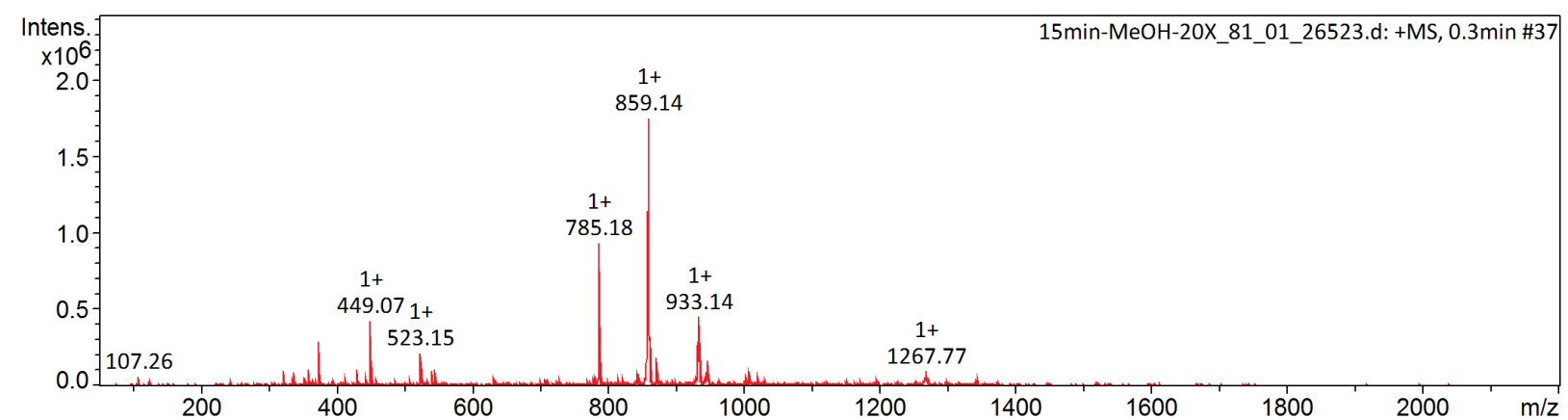

Figure S2. ESI-MS of crude reaction mixture of S1 and phenol after 15 minutes of reaction time. Most abundant adducts are 859.14 , corresponding to $\left[2 \mathbf{S 3} / \mathbf{4}+\mathrm{K}^{+}\right](\mathrm{Calcd} 859.18)$ as well as 785.18 corresponding to $\left[\mathbf{S 1}+\mathbf{S 3} / \mathbf{4}+\mathrm{K}^{+}\right]($Calcd 785.14$)$. The spectra were obtained in positive mode.

${ }^{19}$ F MAS NMR Spectrum of 2:

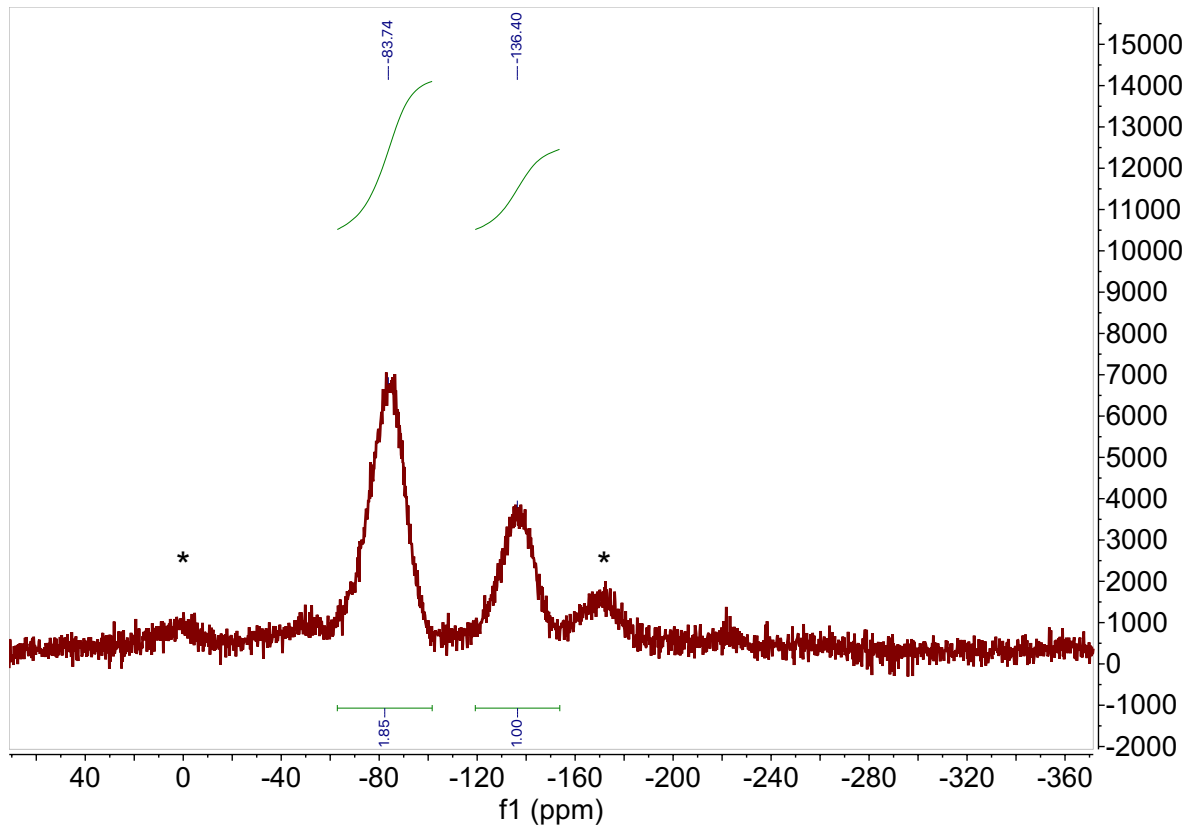

Figure S3. ${ }^{19} \mathrm{~F}$ MAS NMR Spectrum of 2. Starred peaks are spinning side bands correlated to peaks at -83.74 ppm. 


\section{${ }^{19}$ F MAS NMR Spectrum of 2 and ${ }^{19}$ F Solution NMR of S1:}

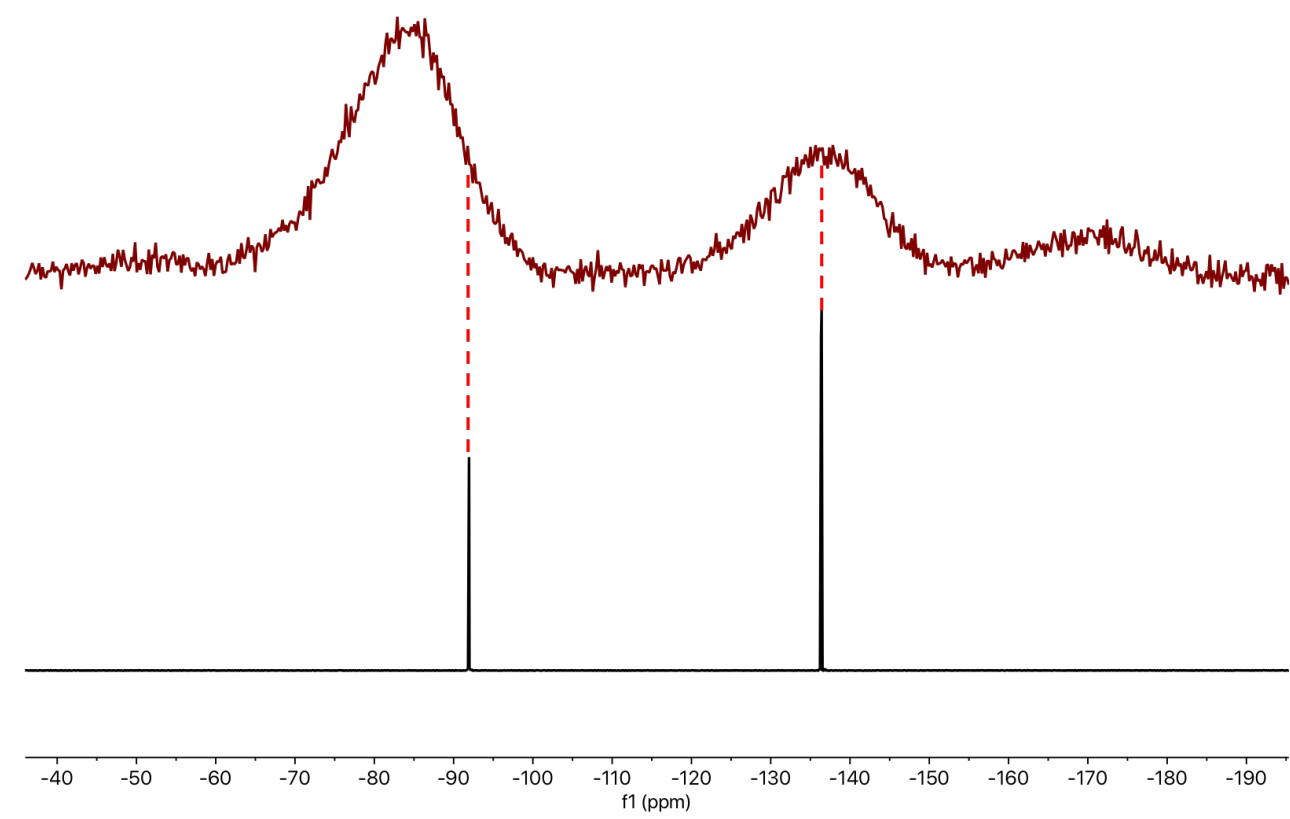

Figure S4. The bottom spectrum represents the ${ }^{19} \mathrm{~F}$ solution NMR of S1. The top spectrum is the ${ }^{19}$ F MAS NMR spectrum of 2 . Red dotted lines were added for clarity. 
${ }^{19}$ F MAS NMR Spectrum of 2 and ${ }^{19}$ F Solution NMR Spectrum of the Model Reaction:
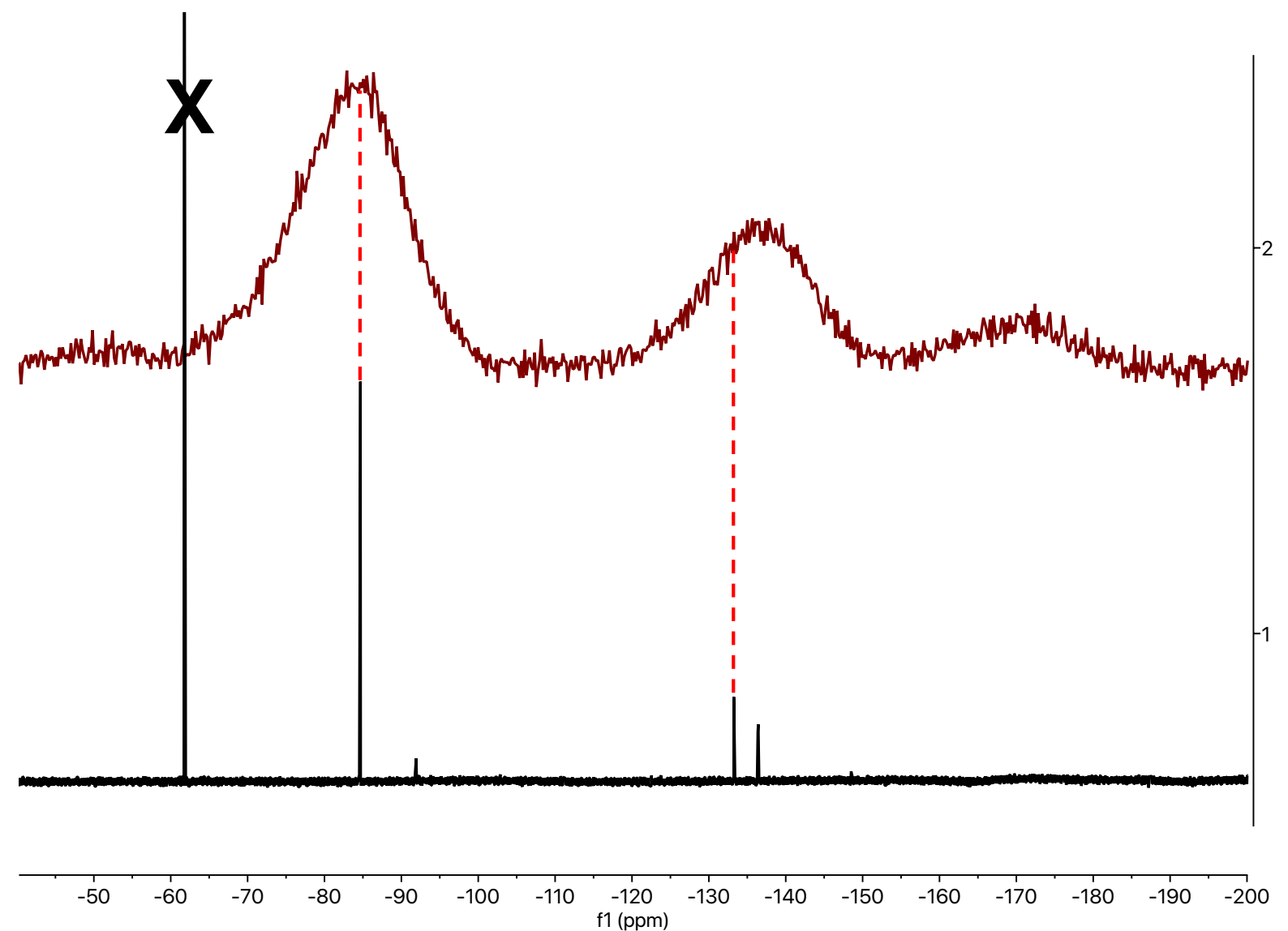

Figure S5. Bottom spectrum: solution-phase ${ }^{19} \mathrm{~F}$ NMR spectrum of the crude reaction mixture of S1 and phenol after 15 minutes of reaction time. This spectrum is overlaid with the ${ }^{19} \mathrm{~F}$ MAS NMR spectrum of 2. The X designates the internal standard peak at $-61.75 \mathrm{ppm}$. For further clarity, red dotted lines were added over peaks corresponding to fluorine signals for S3 and S4. 


\section{${ }^{19}$ F MAS NMR Spectrum of 3:}

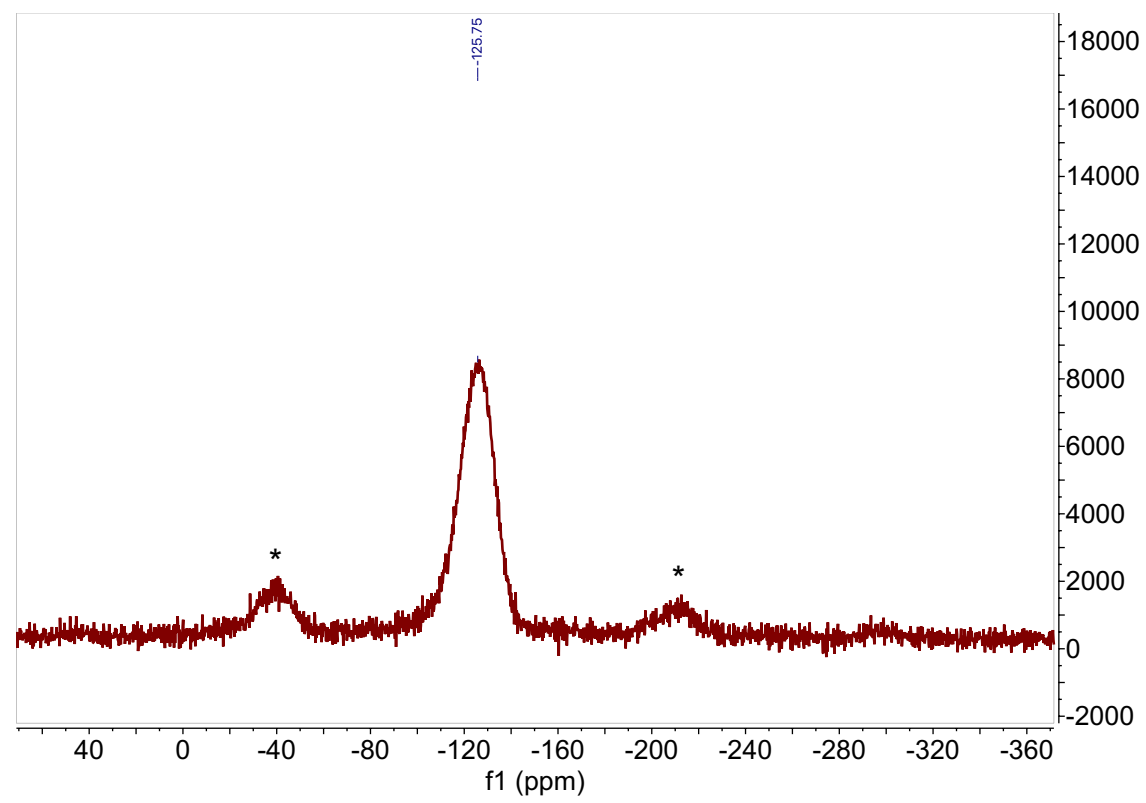

Figure S6. ${ }^{19}$ F MAS NMR spectrum of 3. Starred peaks are spinning side bands correlated to peaks at $-125.75 \mathrm{ppm}$. 


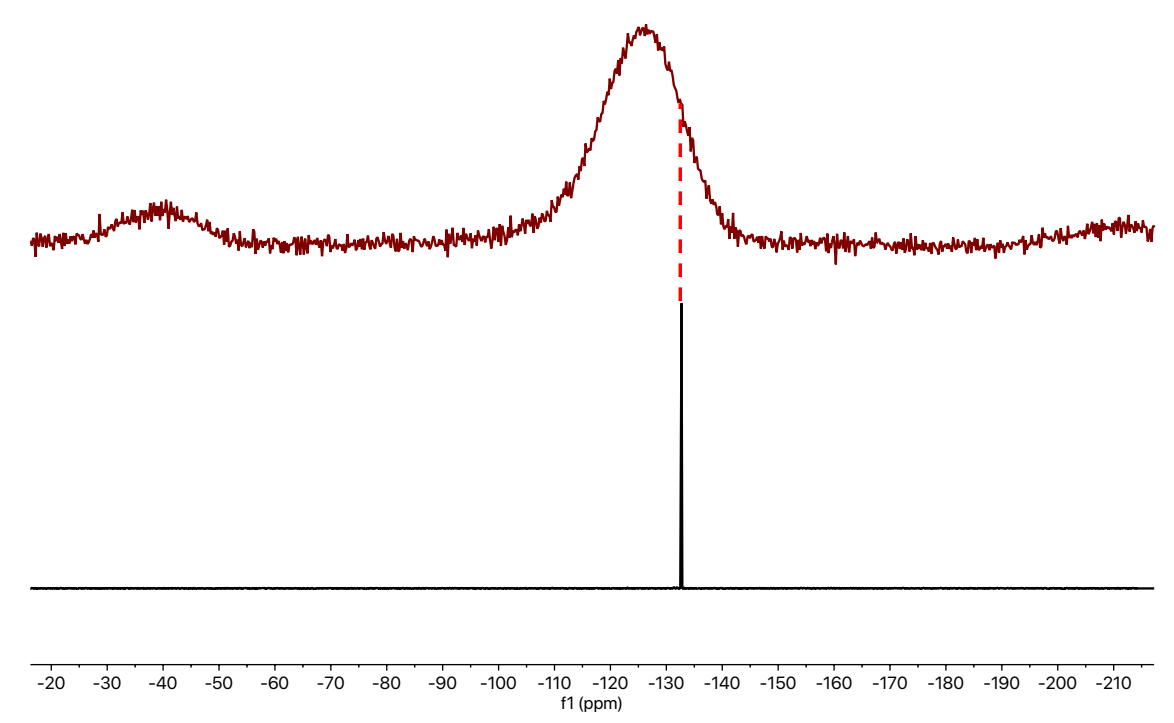

Figure S7. Bottom spectrum: Solution-phase ${ }^{19} \mathrm{~F}$ NMR spectrum of the crude reaction mixture of S2. This spectrum is overlaid with the solid-state ${ }^{19}$ F MAS NMR spectrum of 3 .

\section{${ }^{19}$ F MAS NMR Spectroscopy Discussion:}

These experiments were performed to gain insight into the termination and defects in the polymers by comparing their ${ }^{19} \mathrm{~F}$ MAS NMR spectra to those of model compounds. The spectrum of 2 features two resonances centered at -83.7 and $-136.4 \mathrm{ppm}$ with an integration ratio of $2: 1$. To determine if these resonances correspond to the presence of orthogonal fluorines, this spectrum was compared to the ${ }^{19} \mathrm{~F}$ solution NMR of S1. The doublet of $\mathbf{S 1}$ at $-136.39 \mathrm{ppm}$ matches the resonance at $-136.4 \mathrm{ppm}$ of 2 . This peak at $-136.39 \mathrm{ppm}$ corresponds to the fluorine that is orthogonal to the nitrile. The other doublet of $\mathbf{S 1}(-91.92 \mathrm{ppm})$ corresponds to the fluorine orthogonal to the pyridine. This peak does not match the peak at $-83.7 \mathrm{ppm}$ for 2 . We hypothesized 
that this mismatch may be due to overlapping signals from trisubstituted linkers that have unreacted fluorine adjacent to the pyridine. Therefore, we performed a model reaction of $\mathbf{S 1}$ with phenol to obtain $\mathbf{S 3}$ and $\mathbf{S 4}$ (see above). The spectrum of $\mathbf{S 3}$ shows the appearance of a singlet at $-84.7 \mathrm{ppm}$, which is in good agreement with the peak of $\mathbf{2}$ at $-83.7 \mathrm{ppm}$. Additionally, the model reaction also produced $\mathbf{S} \mathbf{4}$ with a singlet at $-133.25 \mathrm{ppm}$. This peak is not in good agreement with the spectra of $\mathbf{2}$, suggesting a low abundance of trisubstituted linkers with residual fluorine adjacent to the nitrile. It is possible that this signal at -133.25 is obscured by the signal at $-136.39 \mathrm{ppm}$. However, model reactions suggest that substitution should be most favorable adjacent to the nitrile (see above). Therefore, we believe it is probable that relatively few linkages with substitution patterns similar to $\mathbf{S 4}$ are present in the polymer network. These results suggest that residual flourines are most likely present as either 1,2-disubstituted linkages and as trisubstituted linkages with the residual fluorine adjacent to the pyridine.

In the case of polymer $\mathbf{3}$, the ${ }^{19} \mathrm{~F}$ MAS NMR spectra showcases a distinct peak at -125.75 ppm. This peak does not correspond to model compound $\mathbf{S 2}$, which has orthogonal fluorines. This is most likely due to an abundance of trisubstituted linkages being present in the polymer.

The proper chemical shifts of $\mathbf{S 3}$ and $\mathbf{S} 4$ were determined from ${ }^{19} \mathrm{~F}$ NMR spectra that contained an internal standard (3-(trifluoromethyl)benzonitrile -61.75 ppm).

\section{Elemental Analysis}

$\mathrm{C}, \mathrm{H}$, and $\mathrm{N}$ analysis was performed using a combustion method (Robinson Microlit). Fluorine analysis was conducted using an ion-selective electrode method. Measurements were conducted in duplicate. The ratio of either TFIN or TFN to 1 in each polymer sample was determined by 
comparing the carbon to nitrogen ratio. The number of residual fluorines per TFIN/TFN was calculated based upon the fluorine to nitrogen ratio.

\section{Polymer \\ $\mathrm{H} \%$ \\ $\mathbf{N} \%$ \\ $\mathrm{F} \%$ \\ 2 \\ $65.88+/-0.083 .65+/-0.10$ \\ $6.95+/-0.013 .45+/-0.05$ \\ 3 \\ $66.66+/-0.043 .21+/-0.06$ \\ $6.43+/-0.01$ \\ $3.19+/-0.06$}

Table S3. Elemental composition of $\mathbf{2}$ and $\mathbf{3}$.

E. Thermogravimetric Analysis

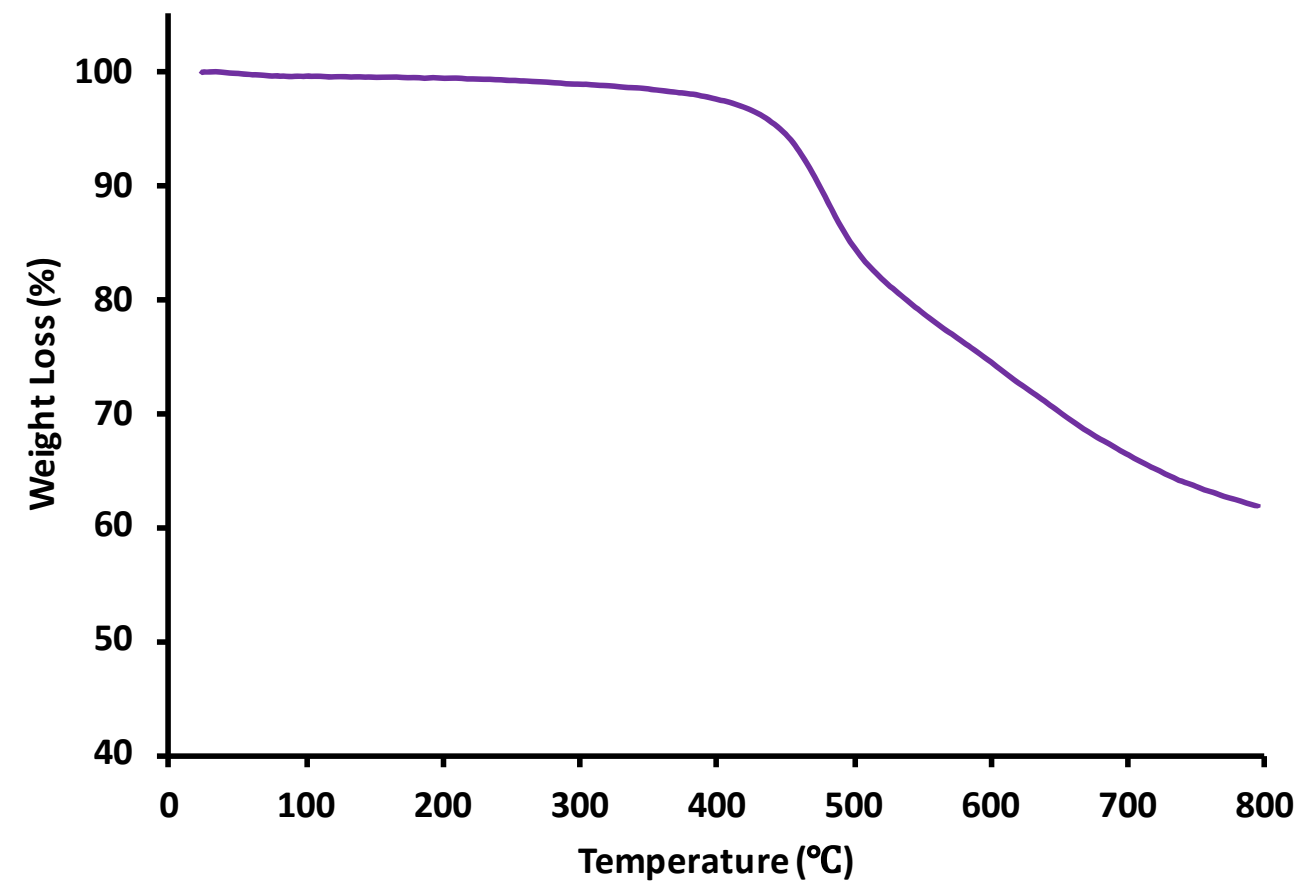

Figure S8. Thermogravimetric analysis of $\mathbf{2}$. 


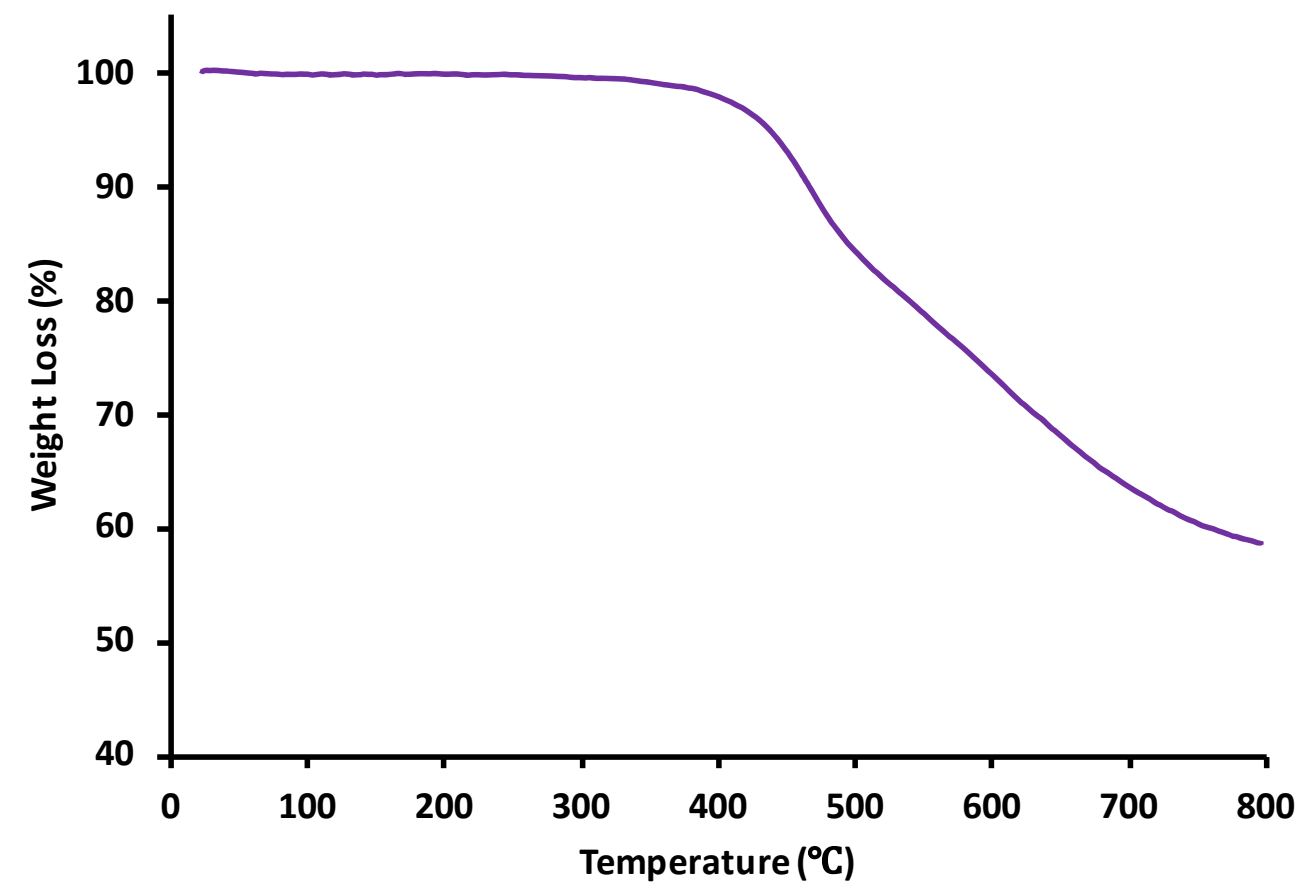

Figure S9. Thermogravimetric analysis of $\mathbf{3}$.

F. Scanning Electron Microscopy

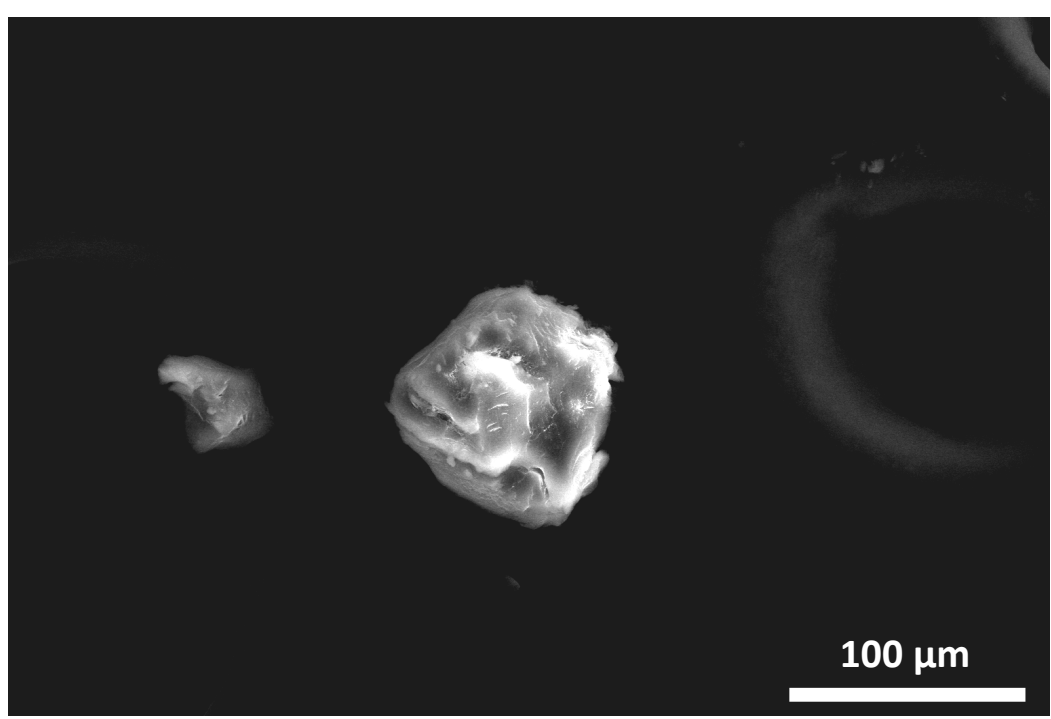

Figure S10. Scanning electron microscopy of $\mathbf{2}$ polymer particles following sieving. 


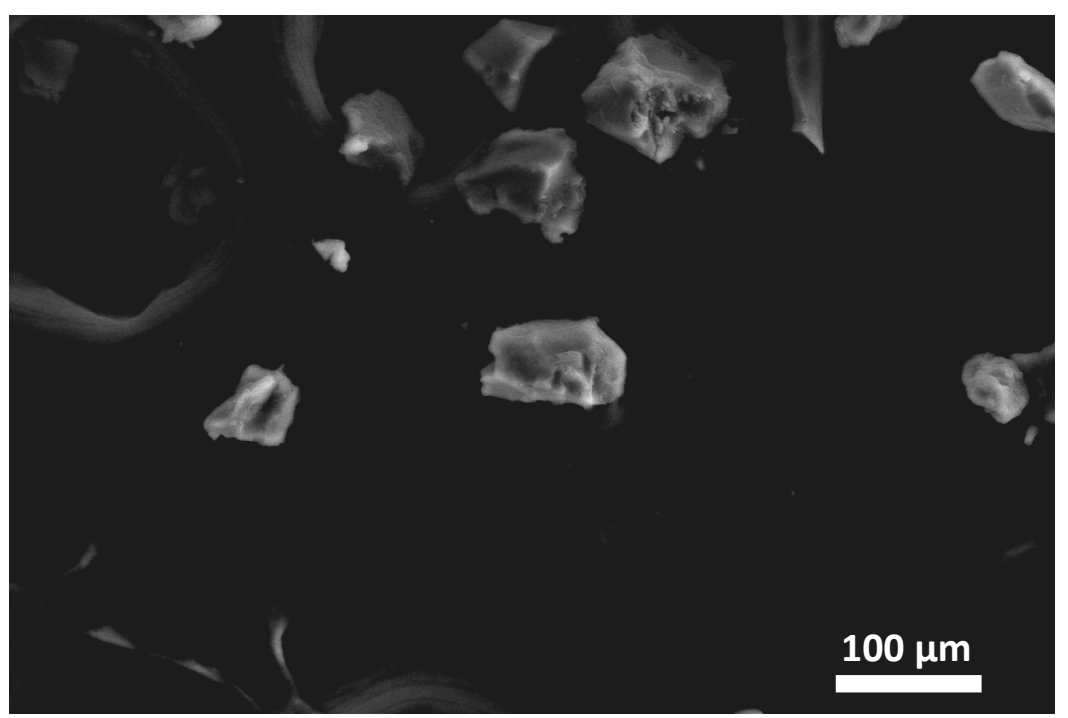

Figure S11. Scanning electron microscopy of 3 polymer particles following sieving.

\section{G. $\mathrm{CHCl}_{3}$ Removal Studies}

\section{General $\mathrm{CHCl}_{3}$ Removal Experiments:}

To prepare a sample for $\mathrm{CHCl}_{3}$ removal, a stock solution $(10 \mathrm{~mL}, 200 \mu \mathrm{g} / \mathrm{L} \mathrm{CHCl}$ in nanopure $\mathrm{H}_{2} \mathrm{O}$ ) was transferred into a $20 \mathrm{~mL}$ glass reaction vial. A suspension of adsorbent in nanopure water (10 mL, $60 \mathrm{mg} / \mathrm{L}$ adsorbent) was added. A Teflon stir bar was added to the solution and the sample was closed and wrapped in parafilm. These samples were made in triplicate and were stirred at $400 \mathrm{rpm}$ for 24 hours. In parallel, two control samples were prepared using nanopure $\mathrm{H}_{2} \mathrm{O}(10 \mathrm{~mL})$ in place of the adsorbent suspension. One of the control samples was stirred at 400 $\mathrm{rpm}$ in tandem with the 3 other experimental samples. The other control was stored at $4{ }^{\circ} \mathrm{C}$. After 24 hours, the four stirred vials were transferred to a glass syringe and filtered with a $0.2 \mu \mathrm{m}$ HPTFE filter directly into a headspace vial $\left(2 \mathrm{~mL}\right.$ liquid per headspace vial). The sample stored at $4{ }^{\circ} \mathrm{C}$ was added directly to a headspace vial. The headspace vials were crimped with silicone lids, and the samples were stored at $4{ }^{\circ} \mathrm{C}$ until analysis by headspace-GCMS (see above). During this 
experimental procedure, we advise that the solution should come into minimal contact with plastic. Minimizing vial headspace was also crucial in inhibiting loss of $\mathrm{CHCl}_{3}$ due to evaporation as we were developing and evaluating the reliability of the above procedure.

\section{Removal Calculations:}

Integration values of analyte peaks were used to calculate percent removal. To confirm no analyte was lost due to evaporation or experimental error, control samples stored at $4{ }^{\circ} \mathrm{C}$ were compared to the control samples stirred overnight. If no significant difference in $\mathrm{CHCl}_{3}$ concentration $(<10 \%)$ was observed between the stored control and the stirred control sample, then the experimental samples were assumed to be unaffected by the experimental procedure. The control sample that was stirred in tandem with the other experimental samples was used as the reference when determining percent removal using the following equation:

$$
\left(1-\frac{\text { Experimental sample integration value }}{\text { Stirred control integration value }}\right) \times 100=\text { Percent Removal }
$$

All removal experiments were calculated this way unless otherwise noted. 


\section{Kinetics of $\mathrm{CHCl}_{3}$ Removal:}

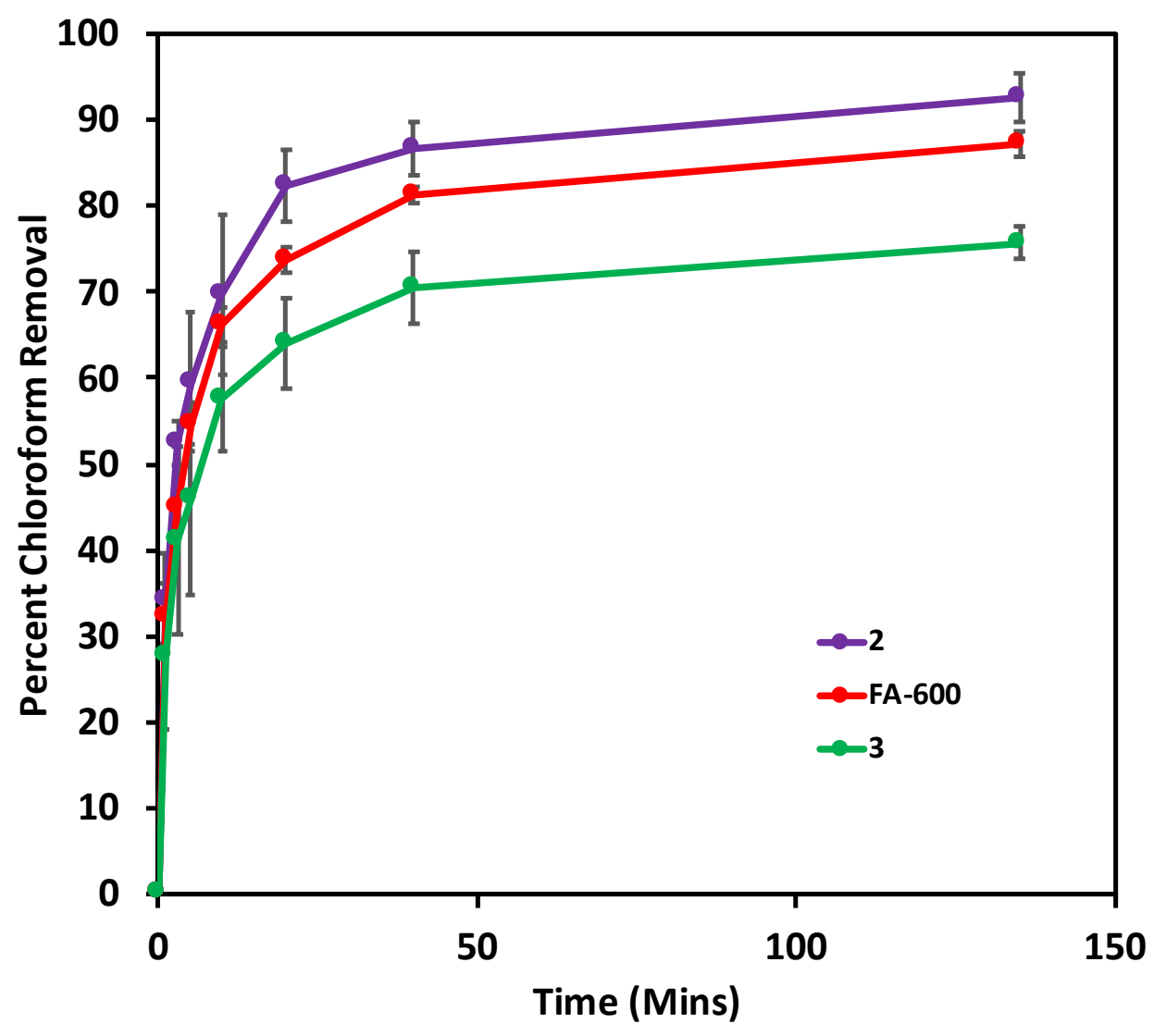

Figure S12. Kinetic removal trace of $\mathrm{CHCl}_{3}(100 \mu \mathrm{g} / \mathrm{L}$ initial concentration) with $\mathbf{2}, \mathbf{3}$, and $\mathbf{F A 6 0 0}$ $(100 \mathrm{mg} / \mathrm{L})$.

A $\mathrm{CHCl}_{3}$ stock solution ( $30 \mathrm{~mL}, 133 \mu \mathrm{g} / \mathrm{L} \mathrm{CHCl}_{3}$ in nanopure water) was transferred into a $40 \mathrm{~mL}$ glass reaction vial. A Teflon stir bar was added to the solution. A suspension of adsorbent $(10 \mathrm{~mL}$, $400 \mathrm{mg} / \mathrm{L}$ in nanopure water) was added to the $\mathrm{CHCl}_{3}$ stock solution and stirred at $400 \mathrm{rpm}$. The timer was started as soon as the $10 \mathrm{~mL}$ suspension was added. Aliquots $(3 \mathrm{~mL})$ were transferred to glass syringes and filtered with HPTFE filters directly into glass headspace vials ( $2 \mathrm{~mL}$ of sample per headspace vial). All headspace vials were crimped with a silicone lid. These aliquots were taken at time points of $1,3,5,10,20,40$, and 135 minutes. In-between each aliquot the vial 
was sealed closed. The zero-time point of this experiment was taken from a mixture of the $\mathrm{CHCl}_{3}$ stock solution $(30 \mathrm{~mL})$ and nanopure water $(10 \mathrm{~mL})$ without adsorbent. This sample was also filtered with a HPTFE filter directly into a headspace vial $(2 \mathrm{~mL})$. This process was repeated in triplicate. The samples were stored at $4{ }^{\circ} \mathrm{C}$ until analysis by headspace-GCMS (see above). Percent removal was calculated using the equation below.

$$
\left(1-\frac{\text { Peak Area of Time Point } X}{\text { Peak Area of Time Point Zero }}\right) \times 100=\text { Percent Removal }
$$

\section{$\mathrm{CHCl}_{3}$ Isotherms:}

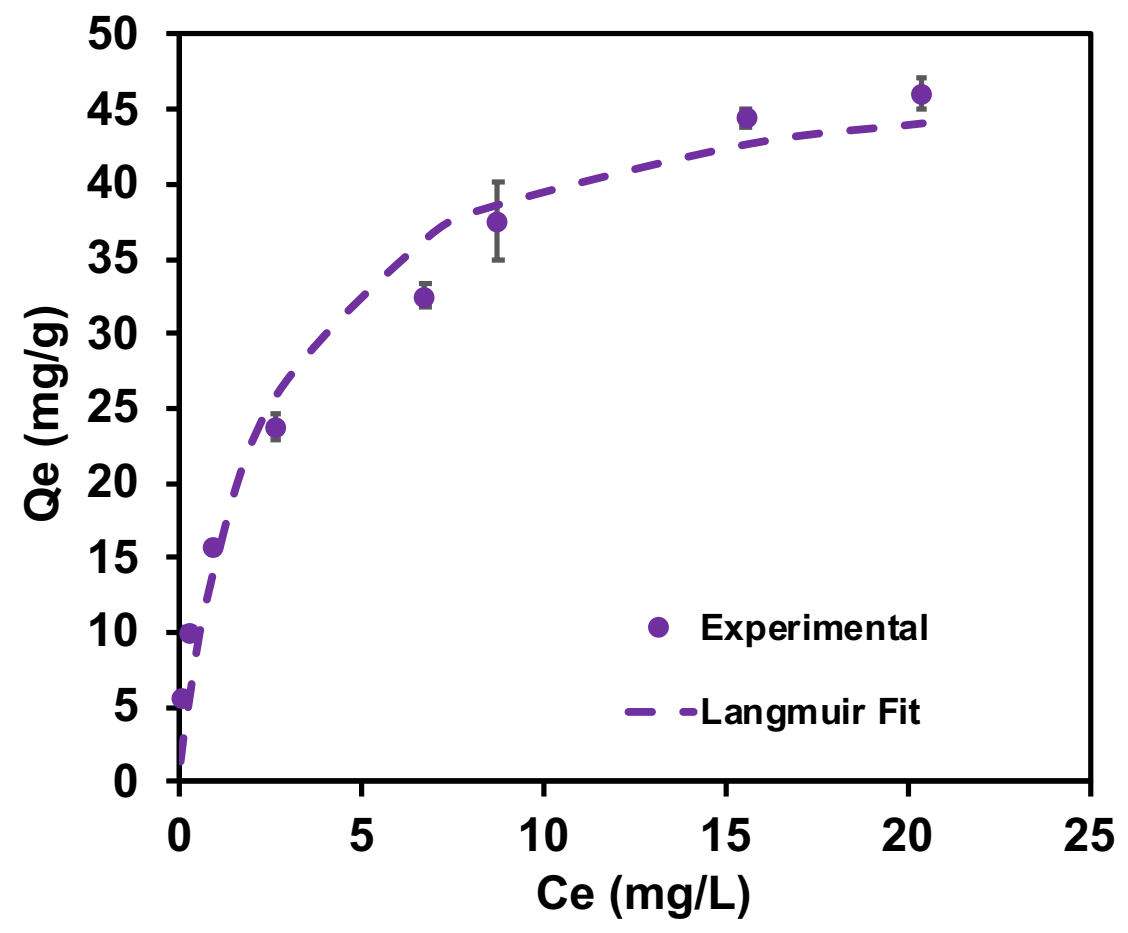

Figure S13. Isotherm of $2(100 \mathrm{mg} / \mathrm{L})$ at high $\mathrm{CHCl}_{3}$ content. The Langmuir fit provided a $\mathrm{R}^{2}$ of 0.987 , a $\mathrm{K}_{\mathrm{L}}$ of $4.91 \cdot 10^{4} \mathrm{M}^{-1}$, and a $\mathrm{Q}_{\max }$ of $49 \mathrm{mg} / \mathrm{g}$. 


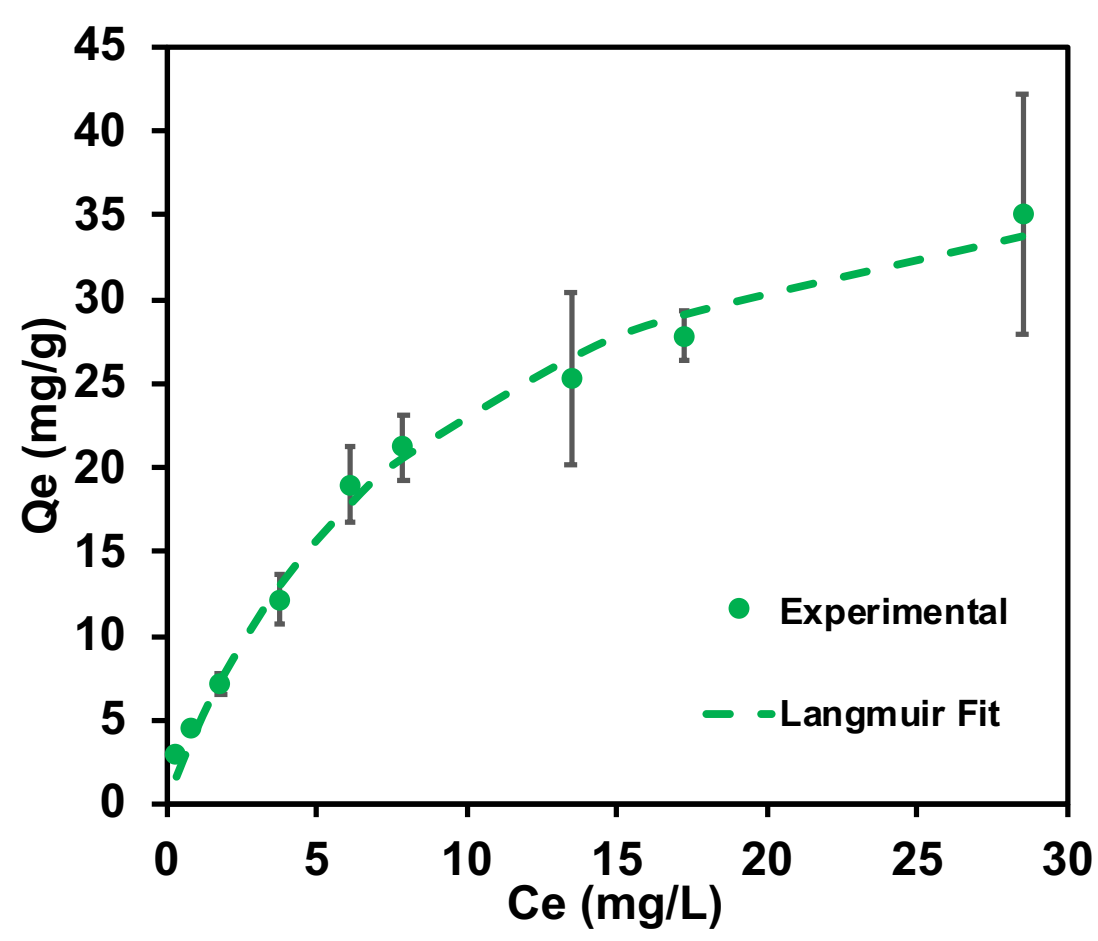

Figure S14. Isotherm of $\mathbf{3}(100 \mathrm{mg} / \mathrm{L})$ at high $\mathrm{CHCl}_{3}$ content. The Langmuir fit provided a $\mathrm{R}^{2}$ of 0.996 , a $\mathrm{K}_{\mathrm{L}}$ of $1.29 \cdot 10^{4} \mathrm{M}^{-1}$, and a $\mathrm{Q}_{\max }$ of $45 \mathrm{mg} / \mathrm{g}$.

High $\mathrm{CHCl}_{3}$ Content Isotherm: $\mathrm{CHCl}_{3}$ stock solutions were made at concentrations of 26.32, 21.05, 13.16, 10.53, 10.53, 5.26, 2.63, 1.32, $0.658 \mathrm{mg} / \mathrm{L}$ for 2 and concentrations of $33.7,21.05,16.85,10.53,8.43,5.26,2.63,1.32,0.658 \mathrm{mg} / \mathrm{L}$ for 3. Stock solutions $(19 \mathrm{~mL})$ were pipetted into their respective $20 \mathrm{~mL}$ glass vial. A suspension of adsorbent $(1 \mathrm{~mL}, 2$ $\mathrm{g} / \mathrm{L}$ ) was added to each vial. A Teflon stir bar was added to the solution and the sample was closed and wrapped in parafilm. Each sample concentration was made in triplicate. Samples were stirred at $400 \mathrm{rpm}$ for 24 hours. Two control samples were made with each $\mathrm{CHCl}_{3}$ stock solution $(19 \mathrm{~mL})$ and nanopure water $(1 \mathrm{~mL})$. One of the control samples for each concentration was stirred at $400 \mathrm{rpm}$ in tandem with the 3 other experimental samples. 
The other control was stored at $4{ }^{\circ} \mathrm{C}$. After 24 hours the stirring vials were transferred to a glass syringe and filtered with a $0.2 \mu \mathrm{m}$ HPTFE filter directly into a headspace vial (2 $\mathrm{mL}$ per headspace vial). The sample stored at $4{ }^{\circ} \mathrm{C}$ was added directly to a headspace vial without filtering $(2 \mathrm{~mL})$. All headspace vials were crimped with a silicone lid. The headspace samples were now stored at $4{ }^{\circ} \mathrm{C}$ until analysis by headspace-GCMS (see above).

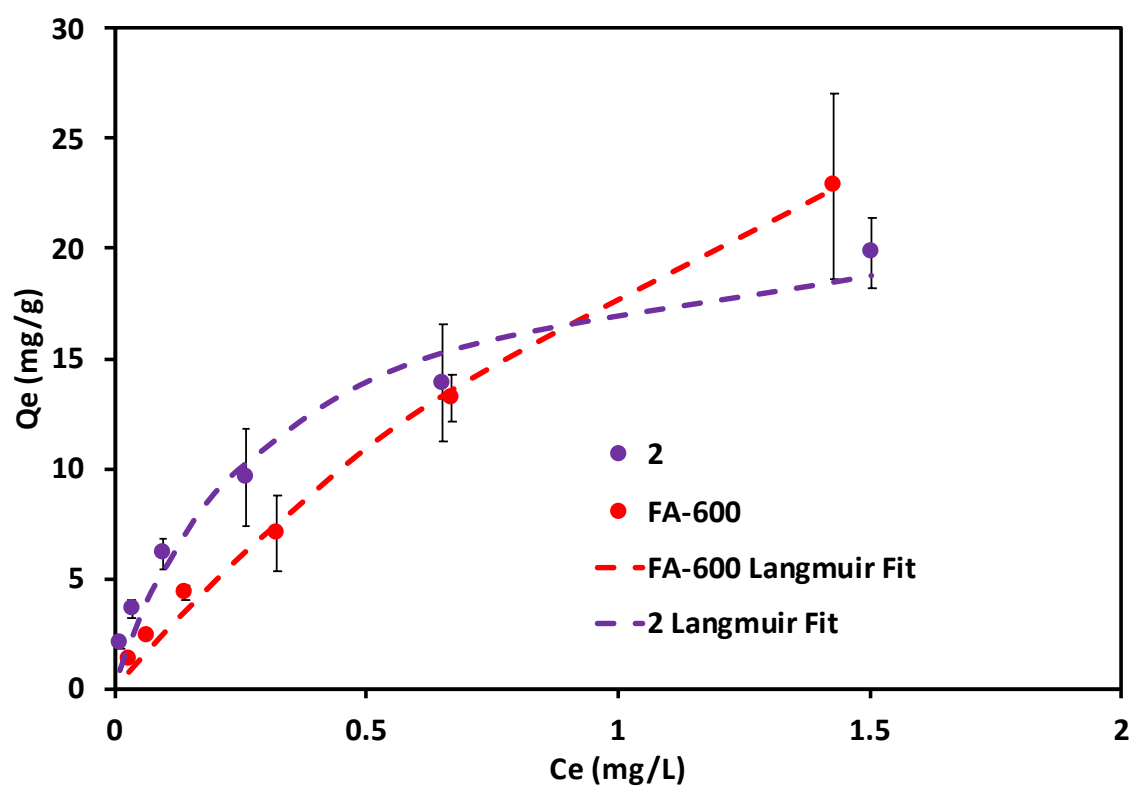

Figure S15. Isotherm of $\mathbf{2}$ and $\mathbf{F A 6 0 0}(25 \mathrm{mg} / \mathrm{L})$ at environmentally relevant $\mathrm{CHCl}_{3}$ content. The Langmuir fit provided a $\mathrm{R}^{2}$ of 0.989 and 0.998 for $\mathbf{2}$ and $\mathbf{F A 6 0 0}$ respectively. The $\mathrm{K}_{\mathrm{L}}$ of $\mathbf{2}$ and FA600 was calculated to be $3.70 \times 10^{5}$ and $3.49 \times 10^{4} \mathrm{M}^{-1}$ respectively.

Isotherm at Environmentally Relevant Concentrations: $\mathrm{CHCl}_{3}$ stock solutions were made at concentrations of $2666,1333,666,332,166$, and $83 \mu \mathrm{g} / \mathrm{L}$. Each stock $(3 \mathrm{~mL})$ was pipetted into their respective vials. A suspension of adsorbent $(1 \mathrm{~mL}, 100 \mathrm{mg} / \mathrm{L})$ was added 
to each vial. A Teflon stir bar was added to the solution and the sample was closed with a PTFE septum and wrapped in parafilm. These samples were made in triplicate and were stirred at $700 \mathrm{rpm}$ for 24 hours. Two control samples for each $\mathrm{CHCl}_{3}$ concentration were made with the $\mathrm{CHCl}_{3}$ stock solutions $(3 \mathrm{~mL})$ and nanopure water $(1 \mathrm{~mL})$. One of the control samples for each concentration was stirred at $700 \mathrm{rpm}$ in tandem with the 3 other experimental samples. The other control was stored at $4{ }^{\circ} \mathrm{C}$. After 24 hours the stirring vials were transferred to a glass syringe and filtered with a $0.2 \mu \mathrm{m}$ HPTFE filter directly into a headspace vial $\left(2 \mathrm{~mL}\right.$ per headspace vial). The sample stored at $4{ }^{\circ} \mathrm{C}$ was added directly to a headspace vial without filtering $(2 \mathrm{~mL})$. All headspace vials were crimped with a silicone lid. The samples were stored at $4{ }^{\circ} \mathrm{C}$ until analysis by headspace-GCMS (see above). A suitable isotherm of $\mathbf{3}$ was not able to be obtained due to lack of significant $\mathrm{CHCl}_{3}$ removal at these conditions.

\section{Isotherm Calculations:}

All isotherms were fit to a Langmuir absorption model with a non-linear least square regression of the equation below.

$$
\begin{aligned}
& \frac{1}{q_{e}}=\frac{1}{Q_{m}}+\frac{1}{C_{e} \times Q_{m} \times K_{L}} \\
& C_{e}: \text { Residual } \mathrm{CHCl}_{3} \text { content }(\mathrm{mg} / \mathrm{L}) \\
& Q_{m}: \text { Maximum absorption capacity }(\mathrm{mg} / \mathrm{g})
\end{aligned}
$$

$q_{e}:$ Amount of $\mathrm{CHCl}_{3}$ removed at equilibrium $(\mathrm{mg} / \mathrm{g})$ 
$K_{L}$ : Langmuir equilibrium constant which represents the ratio absorption and desorption rates $(\mathrm{L} / \mathrm{mg})$

Langmuir fits were able to provide $Q_{m}$ and $K_{L}$ for the adsorbents tested.

\section{TGA experiment for reactivation:}

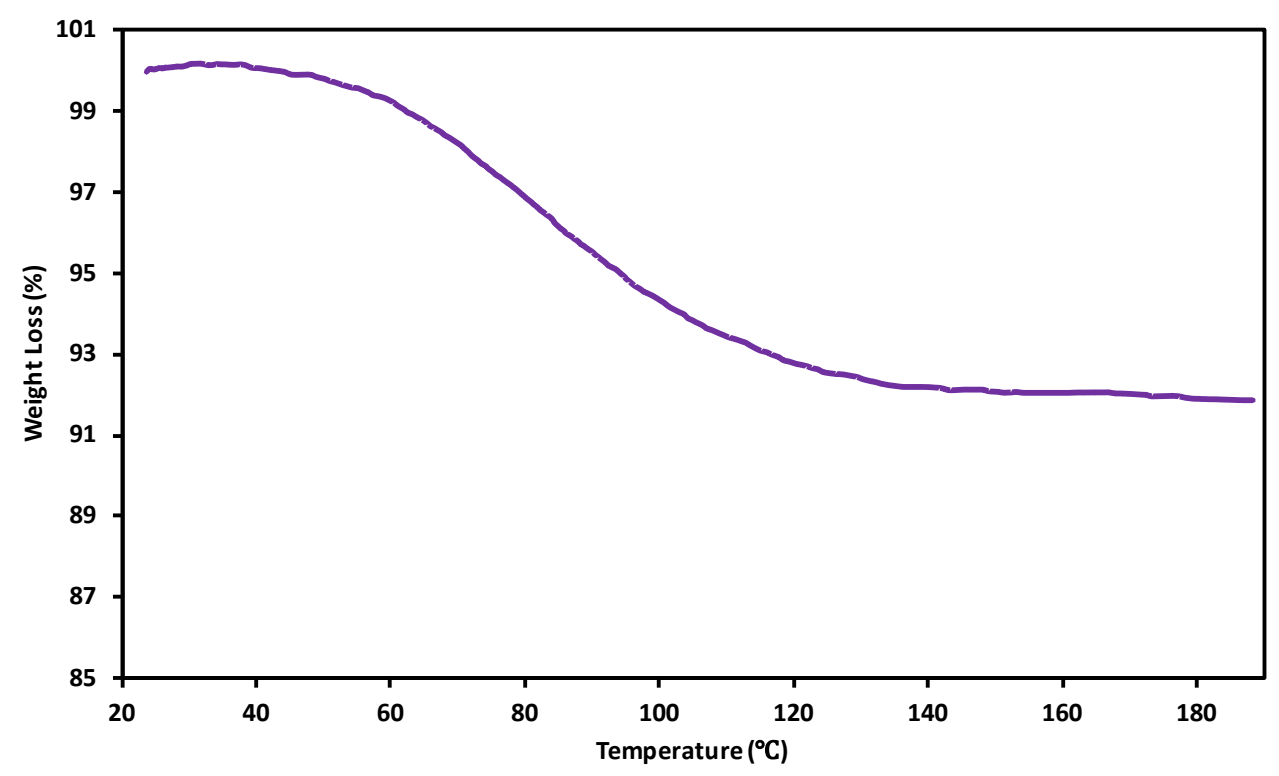

Figure S16. TGA of 2 after exposure to $\mathrm{CHCl}_{3}$ vapor. Mass loss from $60-120{ }^{\circ} \mathrm{C}$ is due to the off gassing of $\mathrm{CHCl}_{3}$.

A suitable regeneration temperature for $\mathbf{2}$ was determined by thermogravimetric analysis (TGA). Adsorbent $(14 \mathrm{mg}$ ) was placed in a $4 \mathrm{~mL}$ vial. The $4 \mathrm{~mL}$ vial with adsorbent was placed in a 20 $\mathrm{mL}$ glass vial containing $\mathrm{CHCl}_{3}(2 \mathrm{~mL})$ for 24 hours. This process led to $\mathrm{CHCl}_{3}$ uptake from the vapor phase by the polymer. After 24 hours the $4 \mathrm{~mL}$ vial with adsorbent was removed and left 
open to air to allow for any excess $\mathrm{CHCl}_{3}$ to leave the vial. TGA was then performed on the polymer using the same procedure as described previously. A transition from $60-120{ }^{\circ} \mathrm{C}$ was observed resulting in a loss of $8 \%$ weight. Tandem GC/MS was able to identify $\mathrm{CHCl}_{3}$ as the species responsible for the loss in weight. The results from these experiments suggested that 120 ${ }^{\circ} \mathrm{C}$ should be sufficient for reactivation of the polymer.

\section{Recycling experiment:}

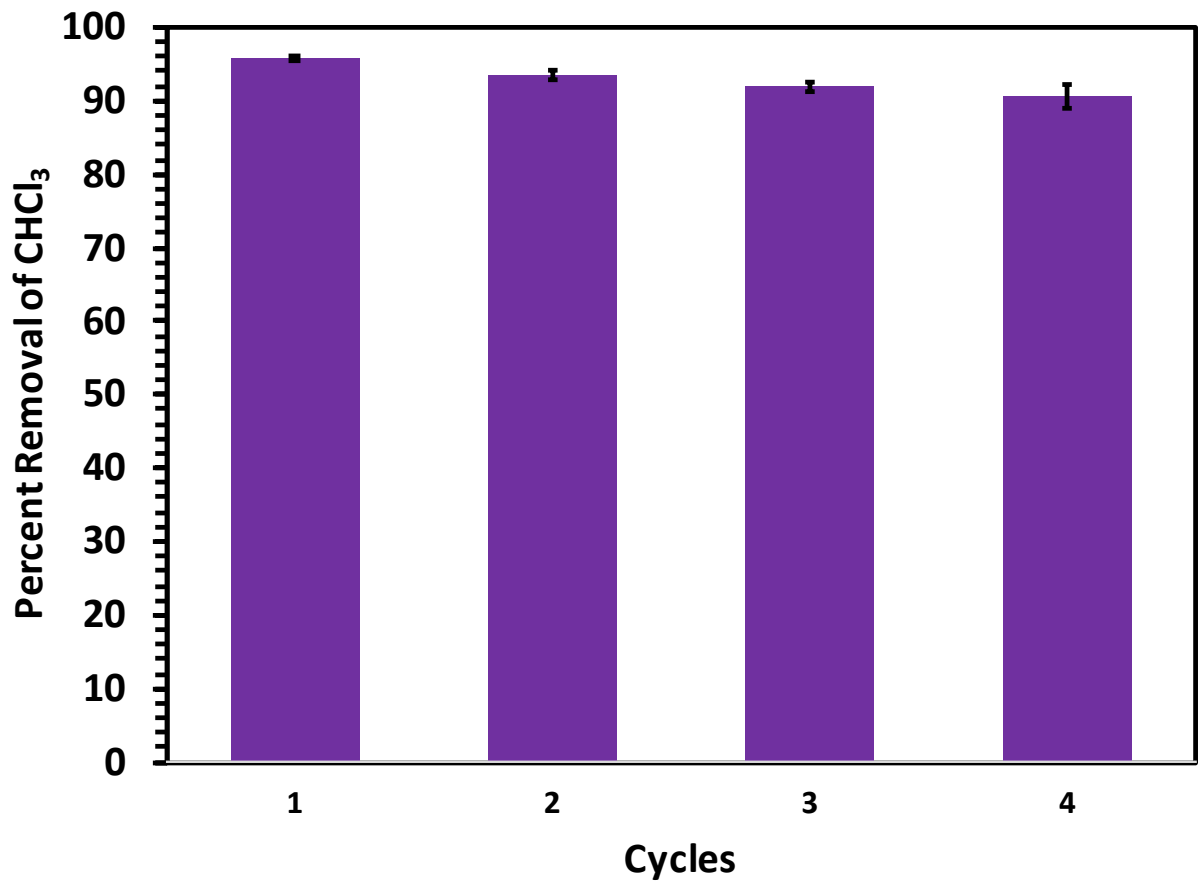

Figure S17. Removal of $\mathrm{CHCl}_{3}(7 \mathrm{mg} / \mathrm{L})$ with $2(1000 \mathrm{mg} / \mathrm{L})$ over four thermal regeneration cycles. The polymer was regenerated under vacuum at $125^{\circ} \mathrm{C}$. 
Conditions were chosen to make polymer recovery feasible and to challenge the polymer at high enough $\mathrm{CHCl}_{3}$ concentration to evaluate reactivation and performance loss. Removal studies were performed in $20 \mathrm{~mL}$ vials with $20 \mathrm{mg}$ of $2(1000 \mathrm{mg} / \mathrm{L})$ in each vial. A stock solution of $\mathrm{CHCl}_{3}(7$ $\mathrm{mg} / \mathrm{L}$ ) was added to the vial along with a Teflon stir bar. The sample was then stirred at $400 \mathrm{rpm}$ for 30 minutes. The vial was removed from stirring for 15 minutes to allow the polymer to settle to the bottom of the vial. $3 \mathrm{~mL}$ of sample was taken from the top of the vial, taking care to not disturb the settled polymer. The aliquot $(3 \mathrm{~mL})$ was added to a glass syringe and filtered through a $0.2 \mu \mathrm{m}$ HPTFE filter into a headspace GC-MS vial $(2 \mathrm{~mL})$. The samples were stored at $4{ }^{\circ} \mathrm{C}$ until analysis by headspace-GCMS. The remaining samples were then filtered to retrieve the polymer. The polymer was returned to the vial and heated to $125^{\circ} \mathrm{C}$ under vacuum $(\sim 40 \mathrm{mmHg})$ for 30 minutes. The polymer was then re-subjected to $\mathrm{CHCl}_{3}(7 \mathrm{mg} / \mathrm{L})$. This process occurs for 4 total cycles. As a control $\mathrm{CHCl}_{3}$ stock solutions $(7 \mathrm{mg} / \mathrm{L})$ was stirred for $30 \mathrm{~min}$ and filtered with a glass syringe and HPTFE filter. Headspace GC-MS was conducted to evaluate residual $\mathrm{CHCl}_{3}$ content (see method above). The control was used as a reference for the percent removal of $\mathrm{CHCl}_{3}$ for each cycle. All measurements were conducted in triplicate. The polymer removed $96 \%$ of the $\mathrm{CHCl}_{3}$ for the first cycle and $91 \%$ for the $4^{\text {th }}$ cycle. This small drop in performance may be due to polymer loss over consecutive filtration operations. Overall, these results suggest that the polymer can be recycled and reused while maintaining a high level of performance.

\section{H. 1,4-Dioxane Removal}

To determine accurate and precise 1,4-dioxane concentrations at $\mu \mathrm{g} / \mathrm{L}$ concentrations, special sample preparation and use of Selected Ion Monitoring (SIM) GC/MS are required according to the EPA method 522. 
A 1 ,4-dioxane stock solution $(1.00 \mathrm{~g} / \mathrm{L}$ in nanopure water $)$ was prepared and diluted sequentially to a final concentration of $100 \mu \mathrm{g} / \mathrm{L}$. 1,4-dioxane samples $(100 \mathrm{~mL}, 100 \mu \mathrm{g} / \mathrm{L}$ in nanopure water) in triplicate were prepared in a plastic bottle charged with a stir bar, then $50 \mathrm{mg}$ or $10 \mathrm{mg}$ of polymer adsorbent (2, 3, FA600 or Ambersorb 560) was added to each sample. As a

control, 1,4-dioxane samples $(100 \mathrm{~mL}, 100 \mu \mathrm{g} / \mathrm{L}$ in nanopure water) with no adsorbent were prepared in triplicate. The samples were stirred overnight at $500 \mathrm{rpm}$. Stirring was stopped, and each adsorbent was allowed to settle for $20 \mathrm{~min}$, after which approximately $80 \mathrm{~mL}$ of the solution was transferred to a $100 \mathrm{~mL}$ brown glass bottle. These samples were packed in a chiller box with an ice bag and shipped to Pace Analytical company for analysis.

\section{1,4-Dioxane Removal in Tap Water:}

Tap water was sourced from water at the Northwestern Technological Institute. The tap water was spiked with $100 \mu \mathrm{g} / \mathrm{L}$ of 1,4-dioxane following the procedure from above. Tap water removal was performed with 2, FA600, and Ambersorb 560 (500 mg/L). Removal experiments were performed in triplicate. However, one sample of $\mathbf{2}$ in tap water was damaged during shipping, such that this measurement was performed in duplicate. 


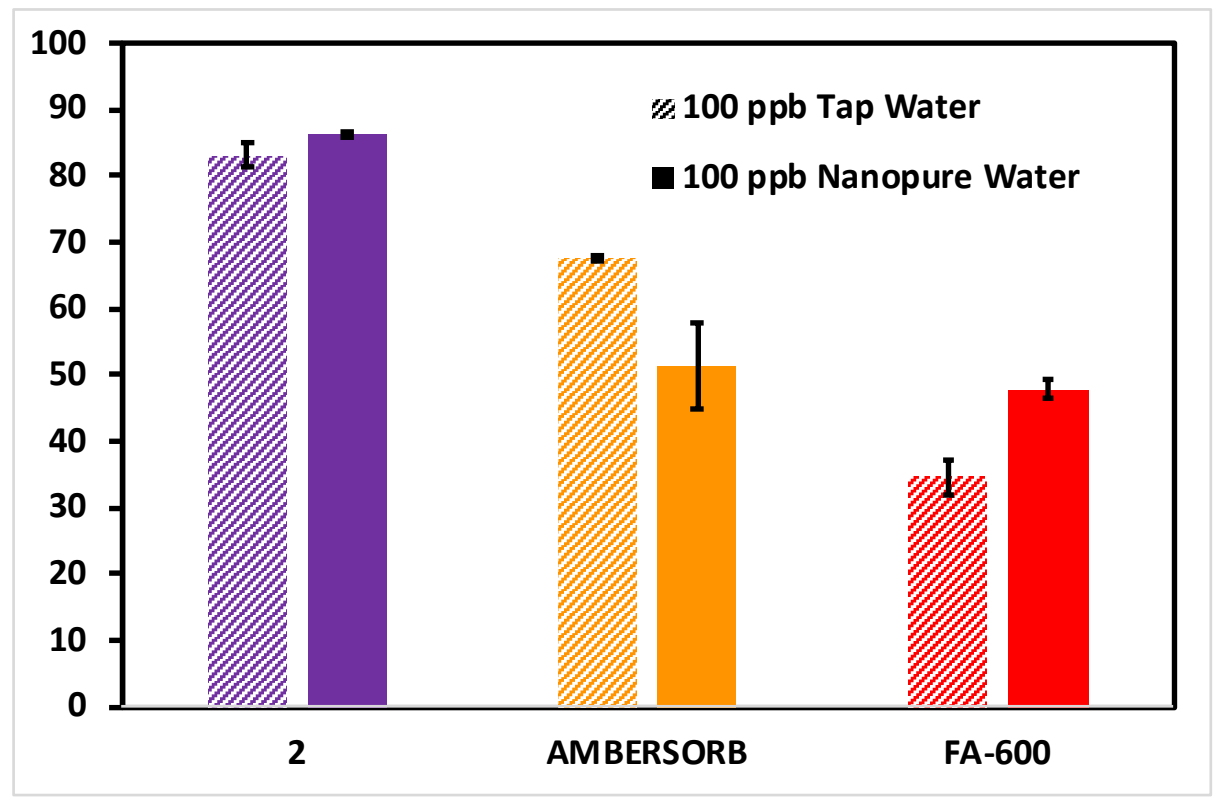

Figure S18. Removal of 1,4-Dioxane (100 $\mu \mathrm{g} / \mathrm{L})$ with 2, Ambersorb 560, and FA600 (500 mg/L) in both tap water and nanopure water.

\section{Standard Curves}

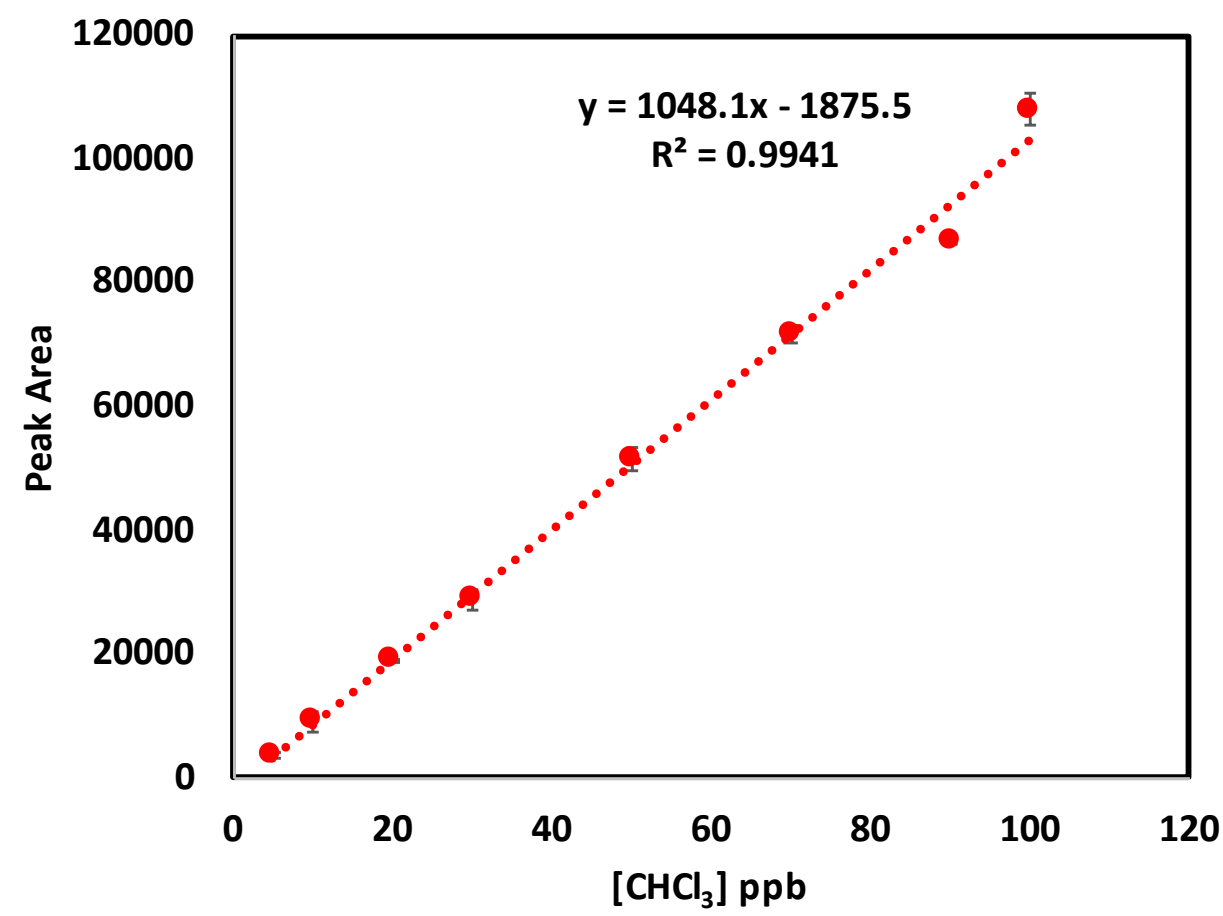

Figure S19. GC-MS $\mathrm{CHCl}_{3}$ standard curve from 5-100 $\mu \mathrm{g} / \mathrm{L}$. 


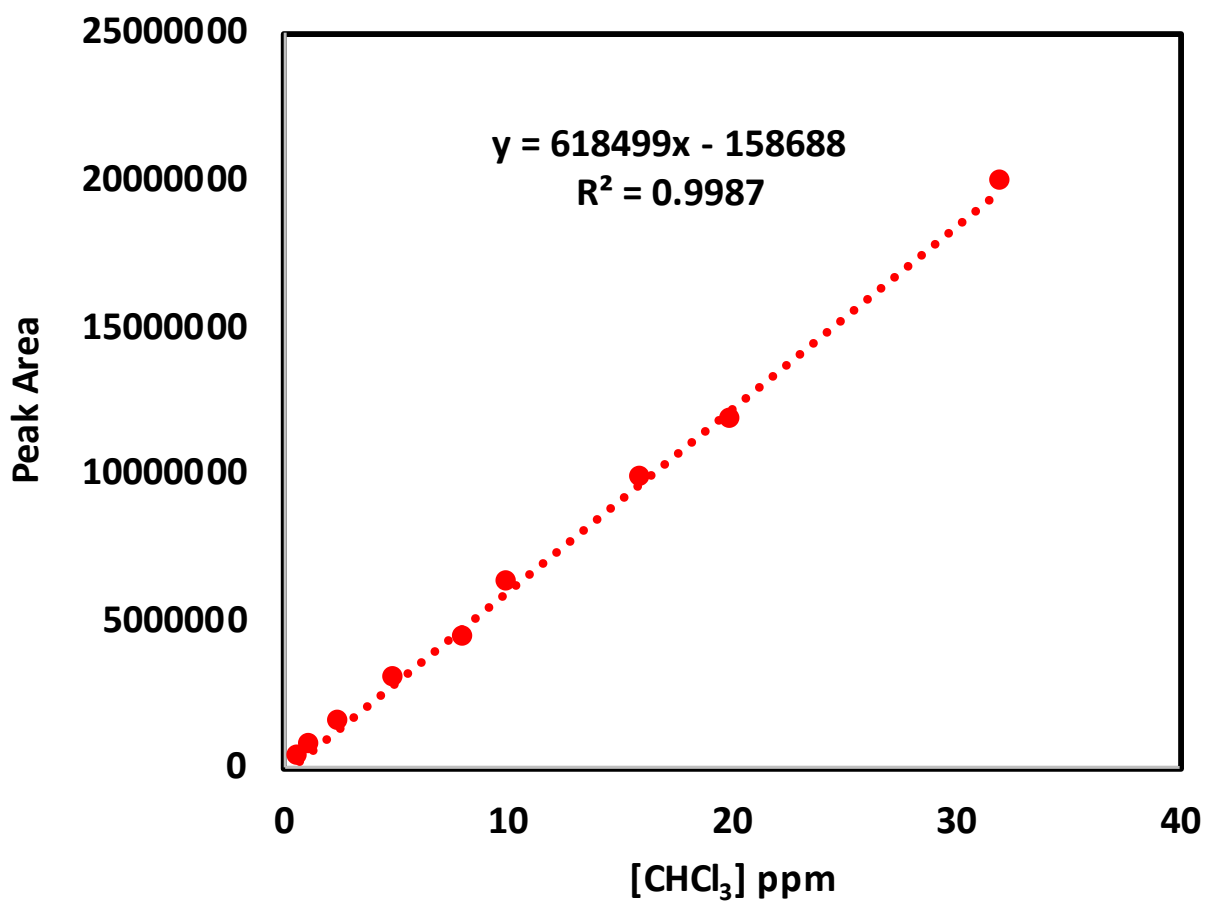

Figure S20. GC-MS $\mathrm{CHCl}_{3}$ standard curve from $0.625-30 \mathrm{mg} / \mathrm{L}$.

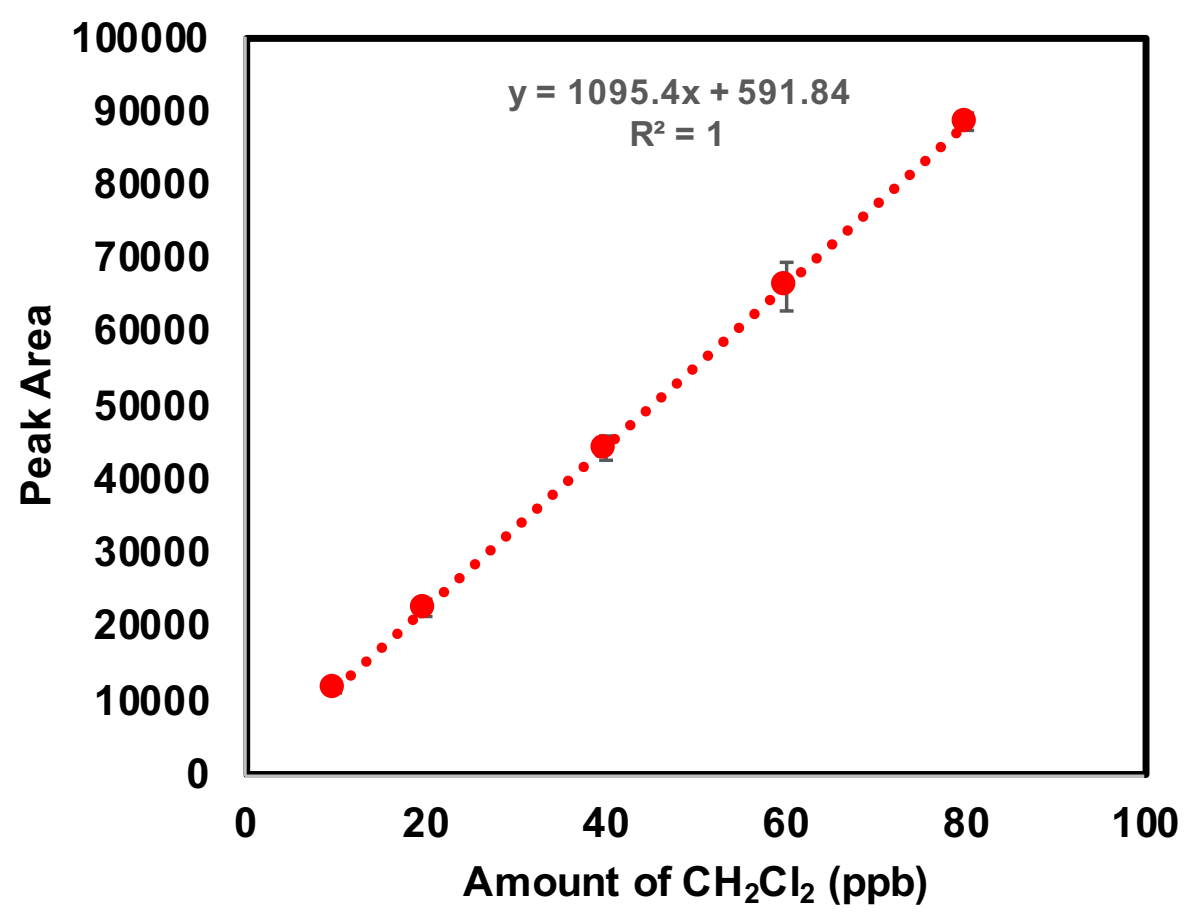

Figure S21. GC-MS $\mathrm{CH}_{2} \mathrm{Cl}_{2}$ standard curve from $10-80 \mu \mathrm{g} / \mathrm{L}$. 


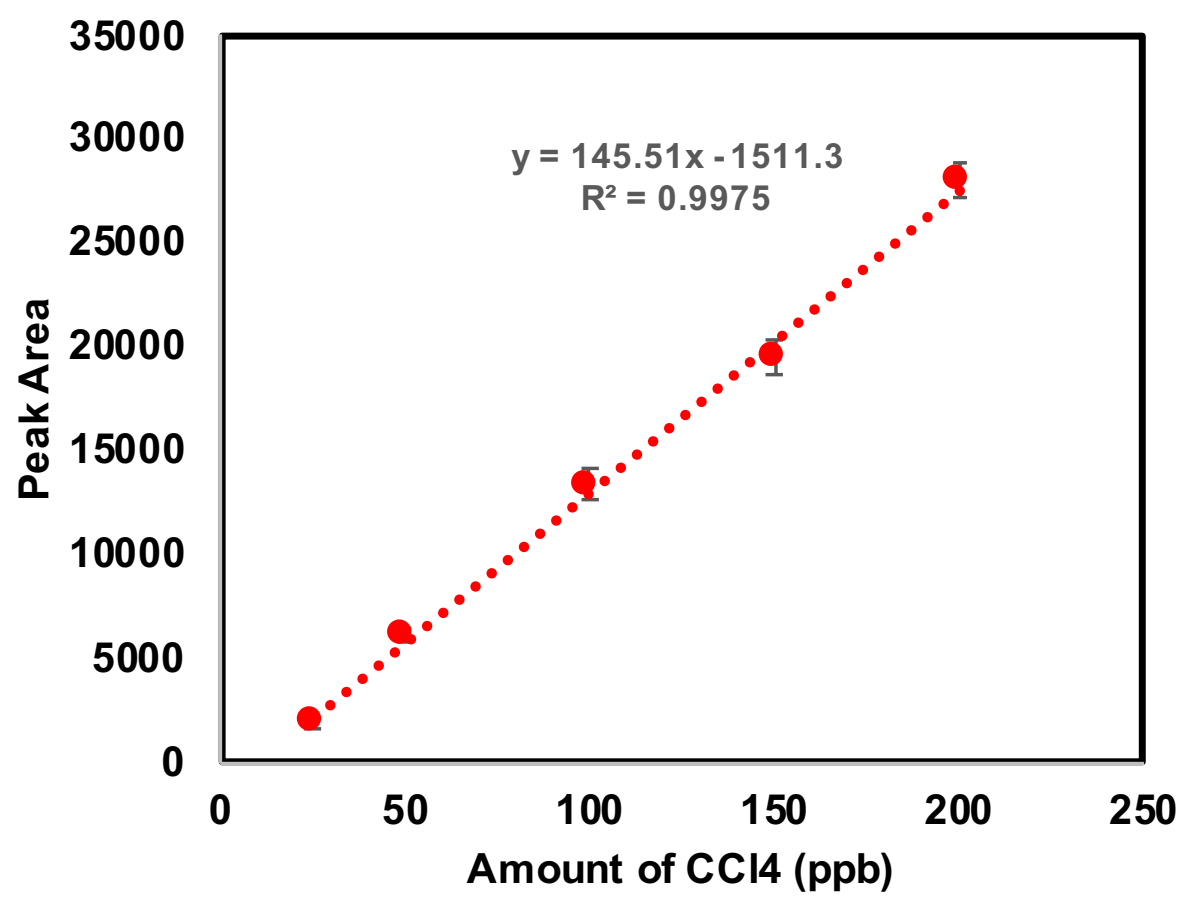

Figure S22. GC-MS CCl 4 standard curve from 10-80 $\mu \mathrm{g} / \mathrm{L}$.

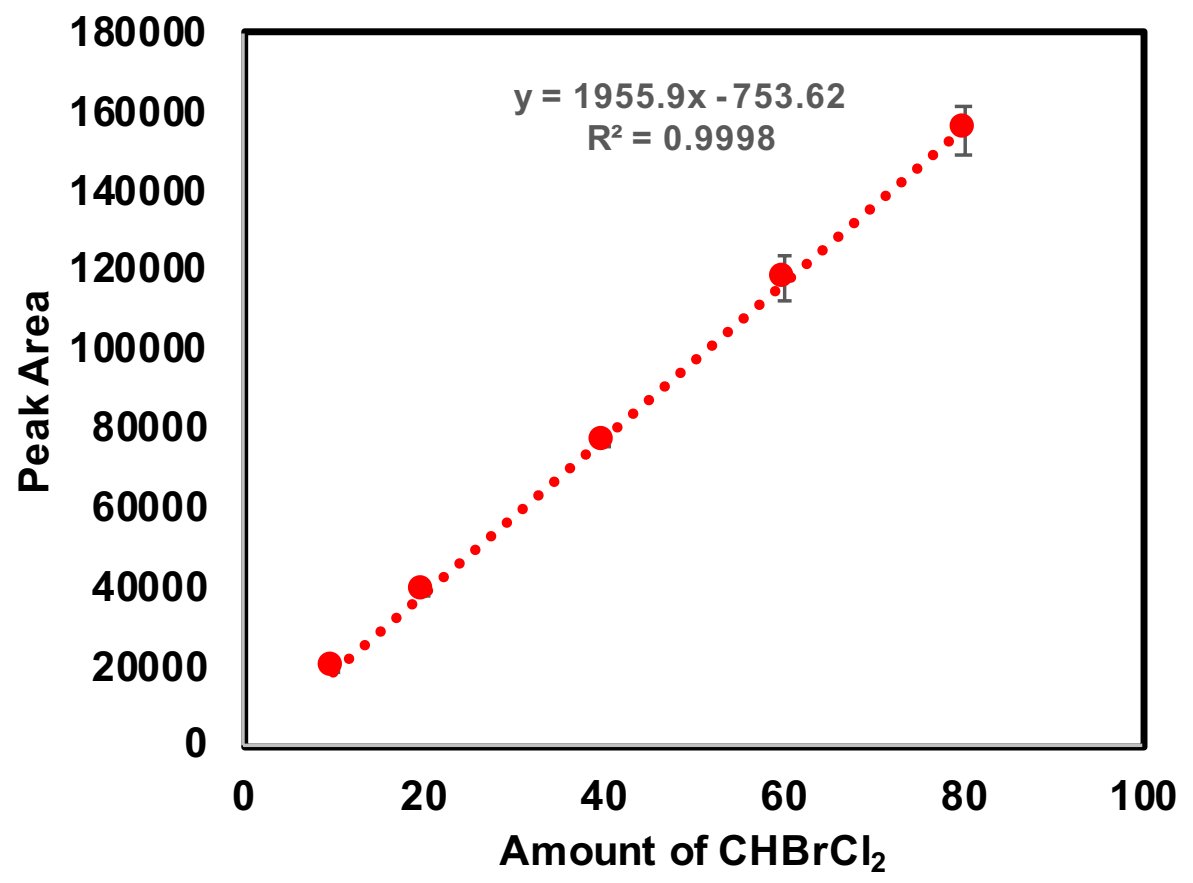

Figure S23. GC-MS $\mathrm{CHBrCl}_{2}$ standard curve from 10-80 $\mu \mathrm{g} / \mathrm{L}$. 


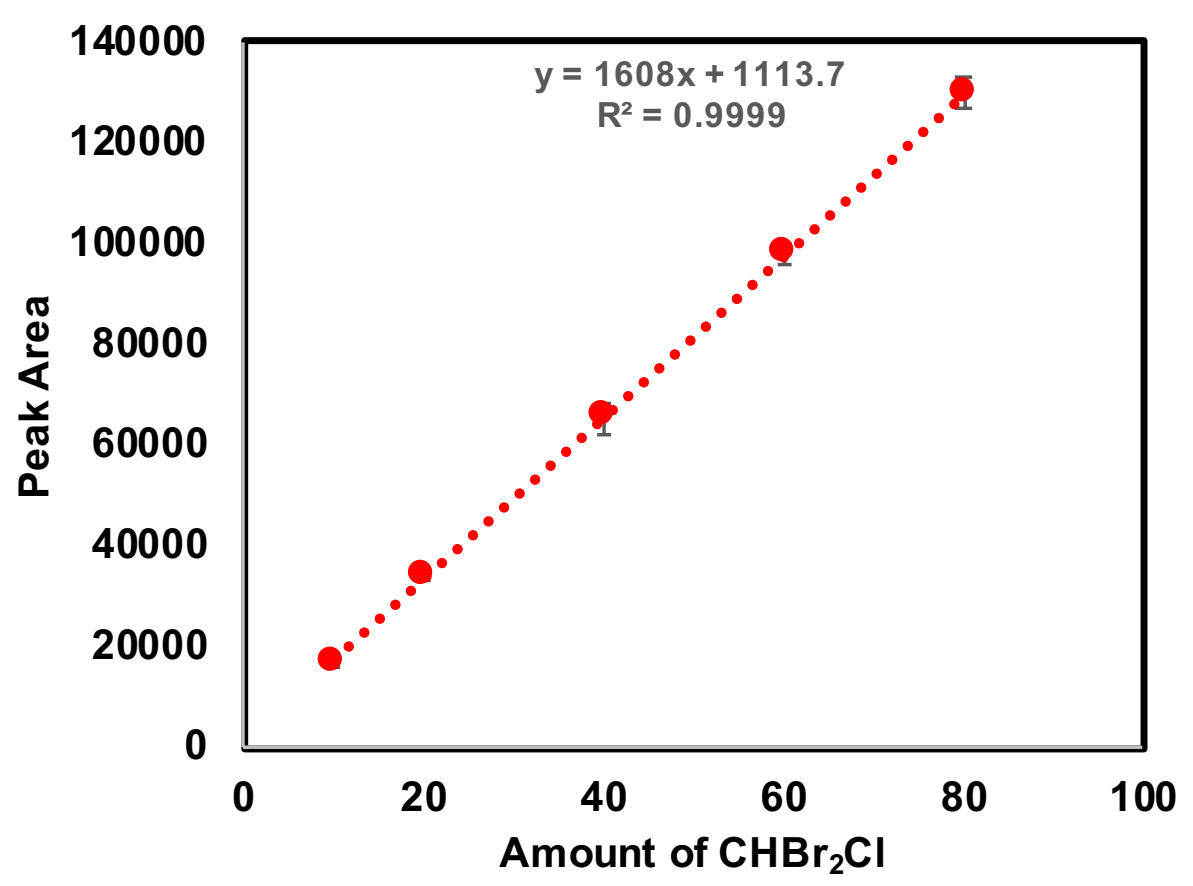

Figure S24. GC-MS CHBr 2 Cl standard curve from $10-80 \mu \mathrm{g} / \mathrm{L}$.

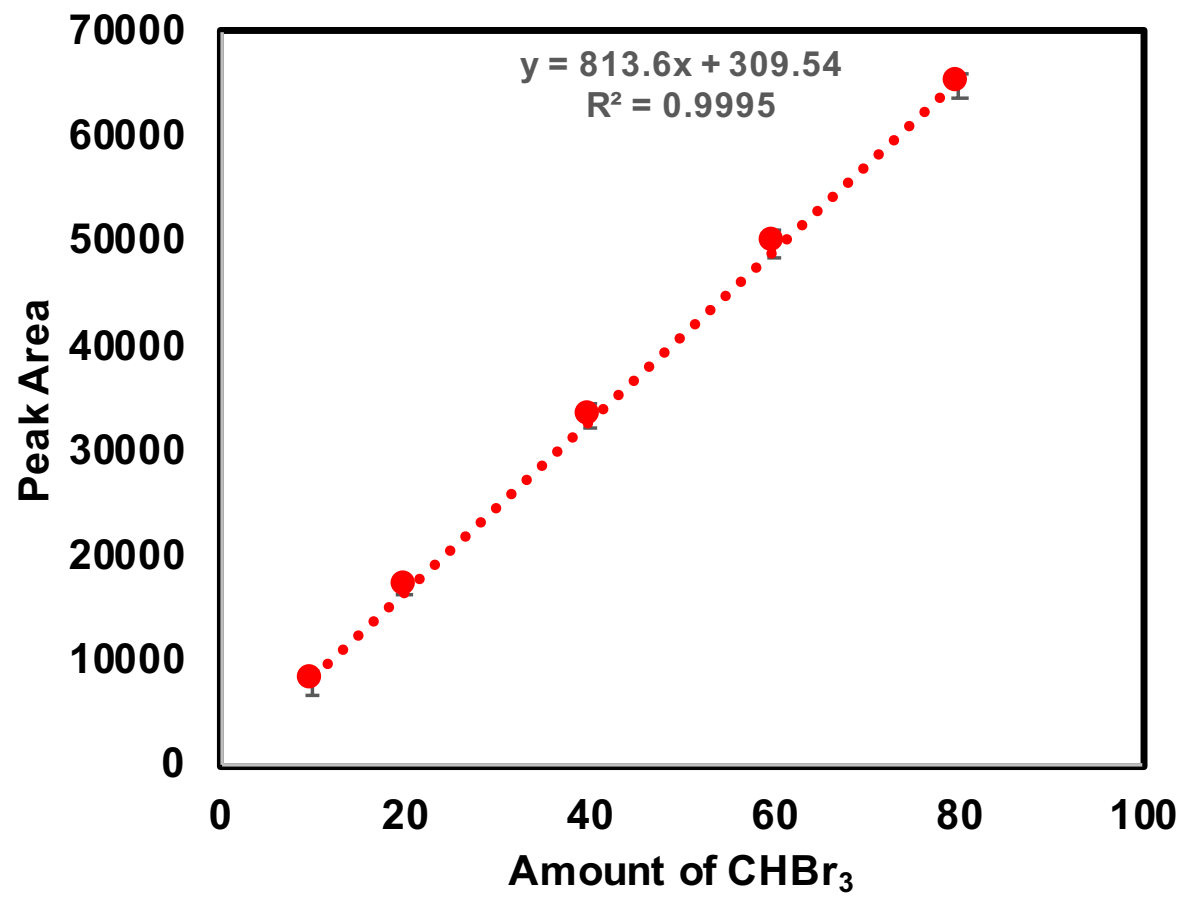

Figure S25. GC-MS CHBr 3 standard curve from $10-80 \mu \mathrm{g} / \mathrm{L}$. 


\section{J. ${ }^{1} \mathrm{H},{ }^{13} \mathrm{C}$, and ${ }^{19} \mathrm{~F}$ NMR Spectra of Synthesized Compounds}

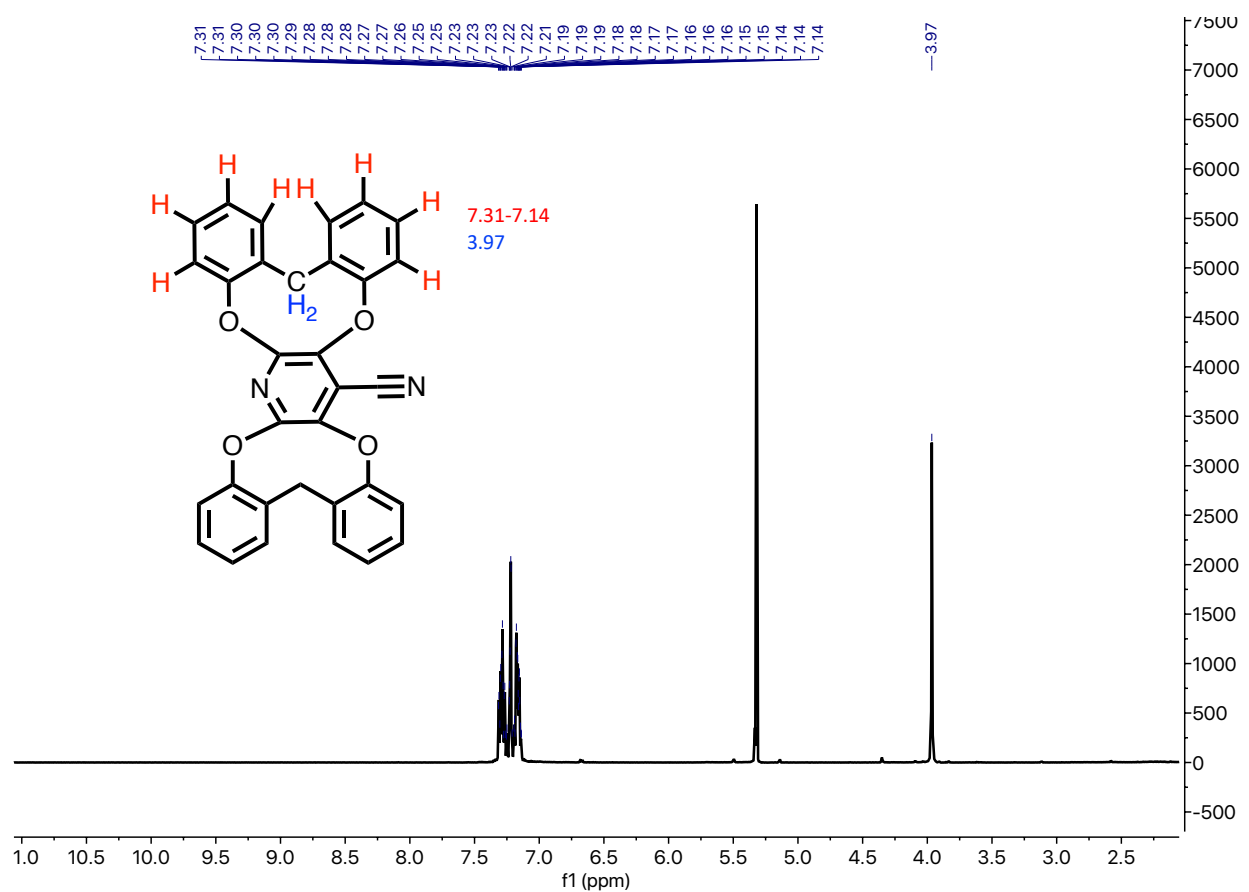

Figure S26. ${ }^{1} \mathrm{H}$ NMR spectrum $\left(500 \mathrm{MHz}, 298 \mathrm{~K}, \mathrm{CD}_{2} \mathrm{Cl}_{2}\right.$ ) of 4

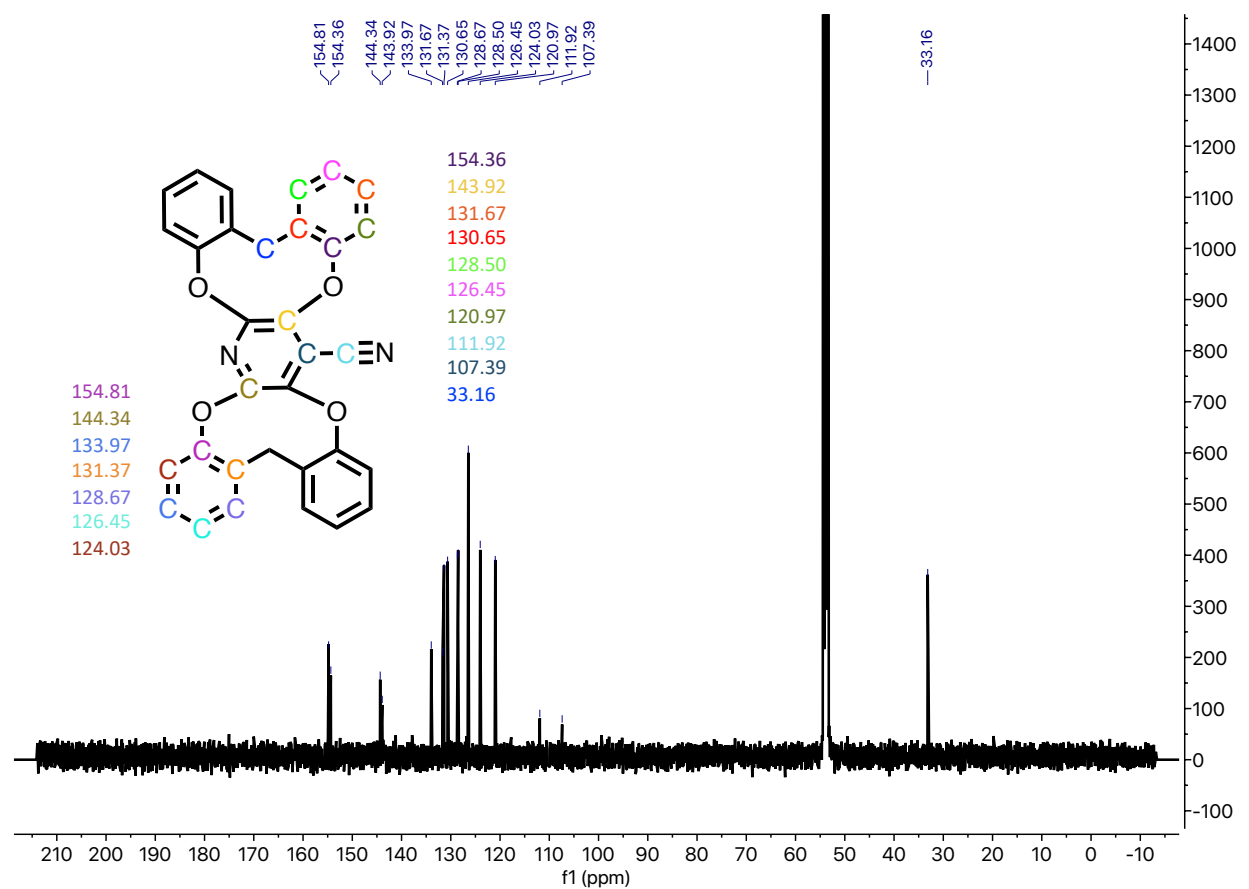

Figure S27. ${ }^{13} \mathrm{C}$ NMR spectrum $\left(126 \mathrm{MHz}, 298 \mathrm{~K}, \mathrm{CD}_{2} \mathrm{Cl}_{2}\right)$ of $\mathbf{4}$ 


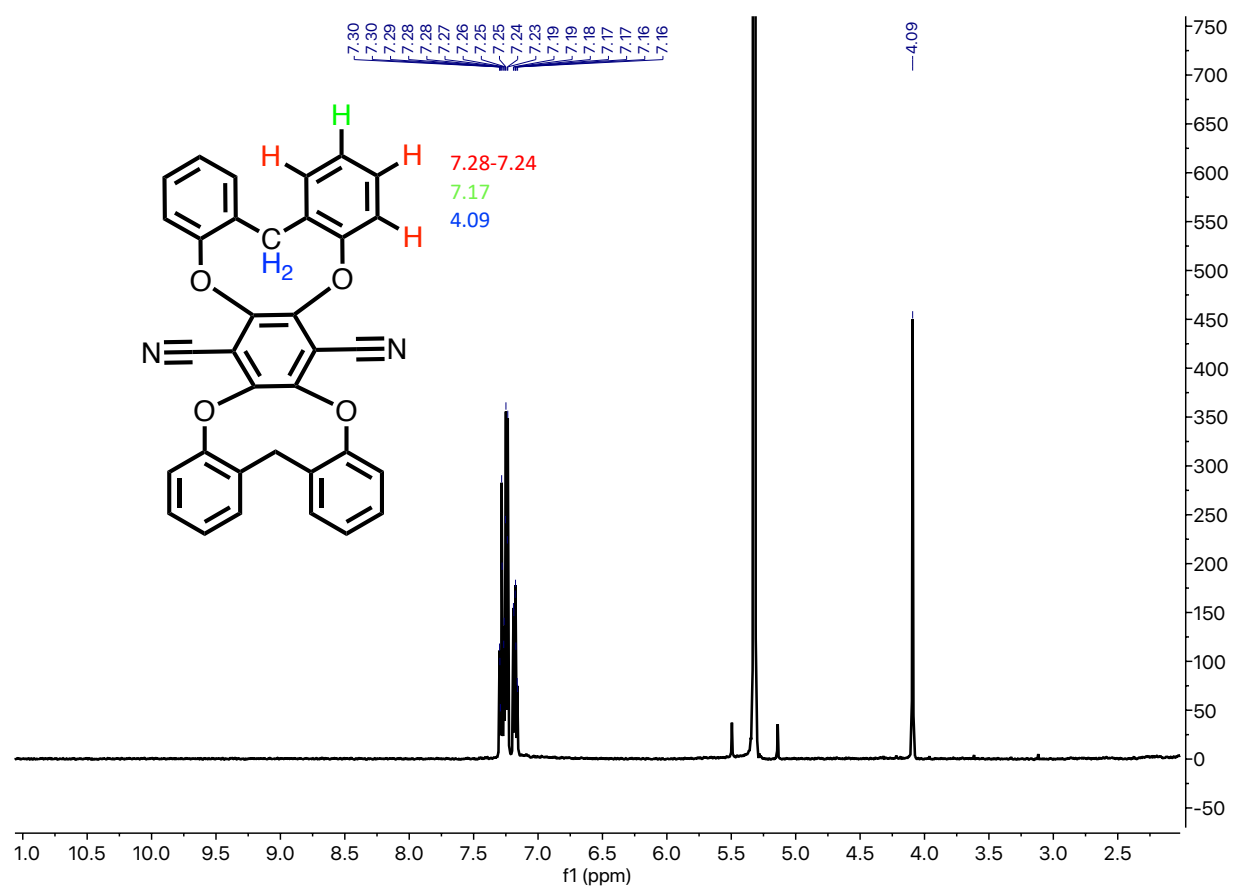

Figure S28. ${ }^{1} \mathrm{H}$ NMR spectrum $\left(500 \mathrm{MHz}, 298 \mathrm{~K}, \mathrm{CD}_{2} \mathrm{Cl}_{2}\right)$ of 5

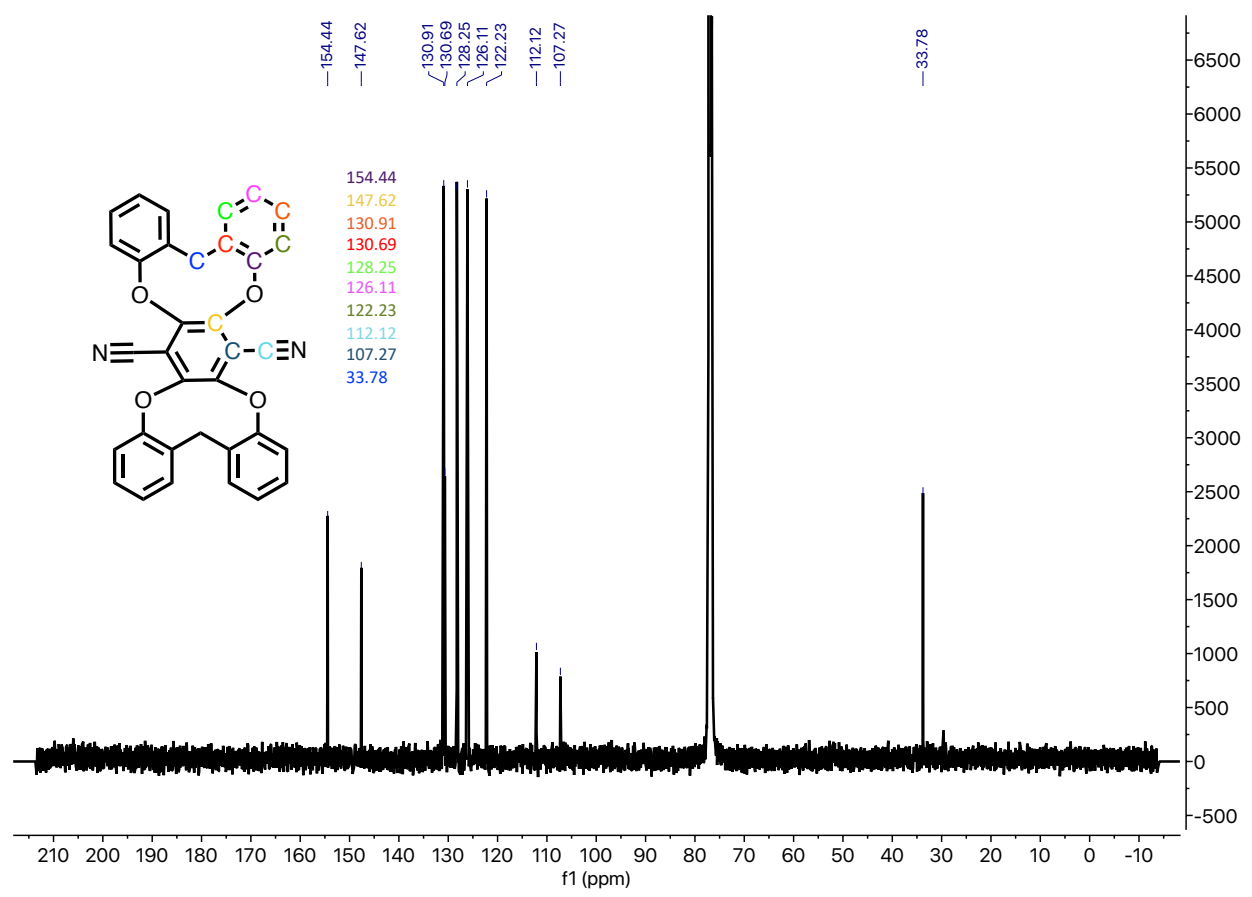

Figure S29. ${ }^{13} \mathrm{C}$ NMR spectrum $\left(126 \mathrm{MHz}, 298 \mathrm{~K}, \mathrm{CDCl}_{3}\right)$ of $\mathbf{5}$ 


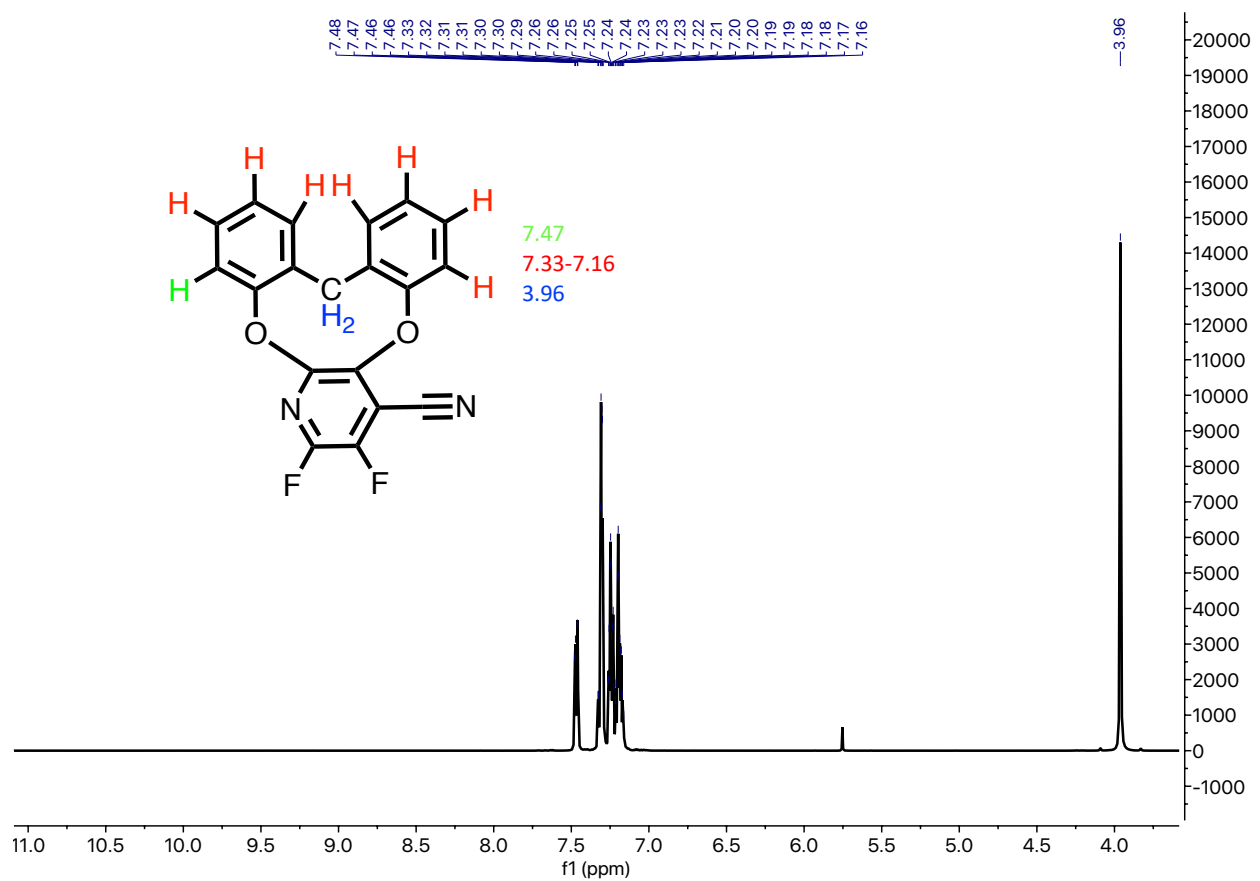

Figure S30. ${ }^{1} \mathrm{H}$ NMR spectrum (500 MHz, 298K, DMSO) of S1

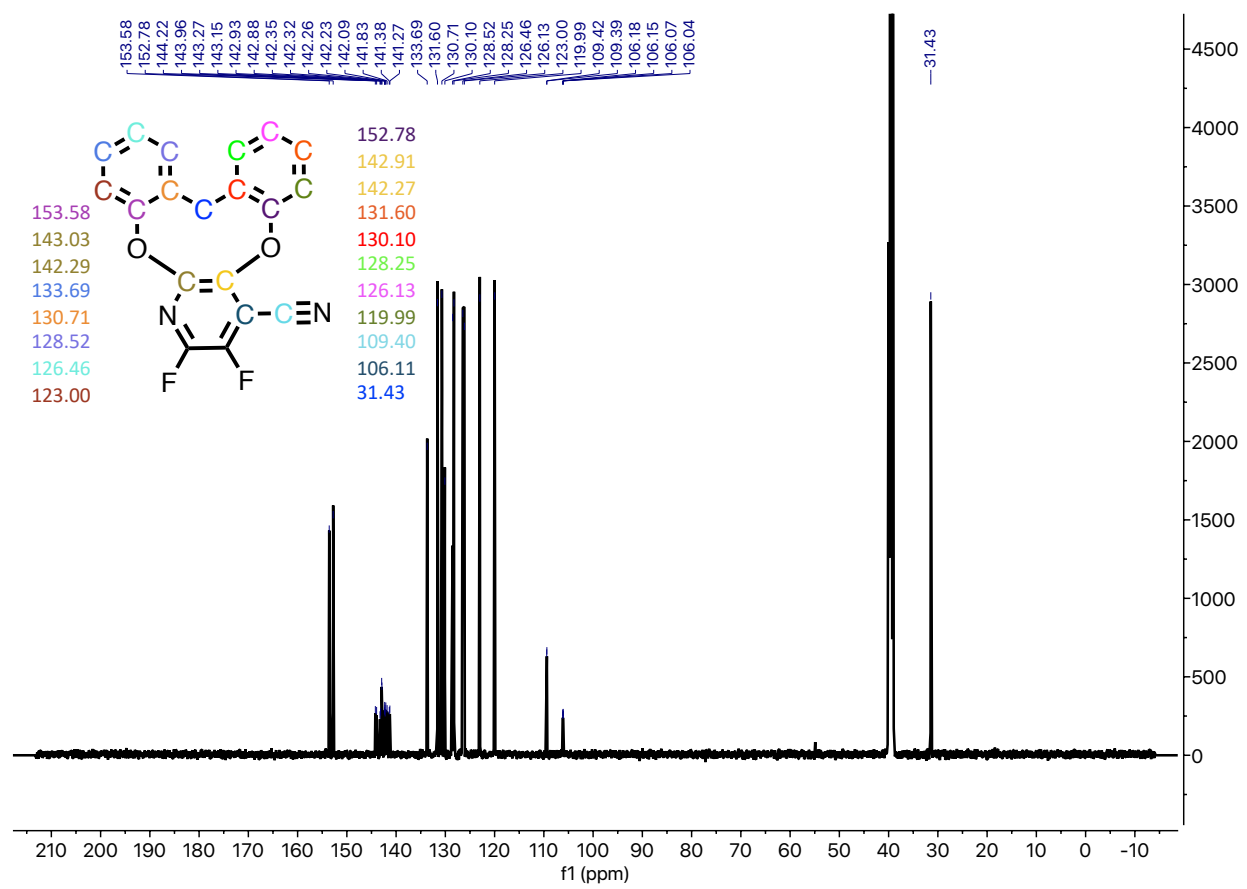

Figure S31. ${ }^{13} \mathrm{C}$ NMR spectrum (126 MHz, 298K, DMSO) of S1 


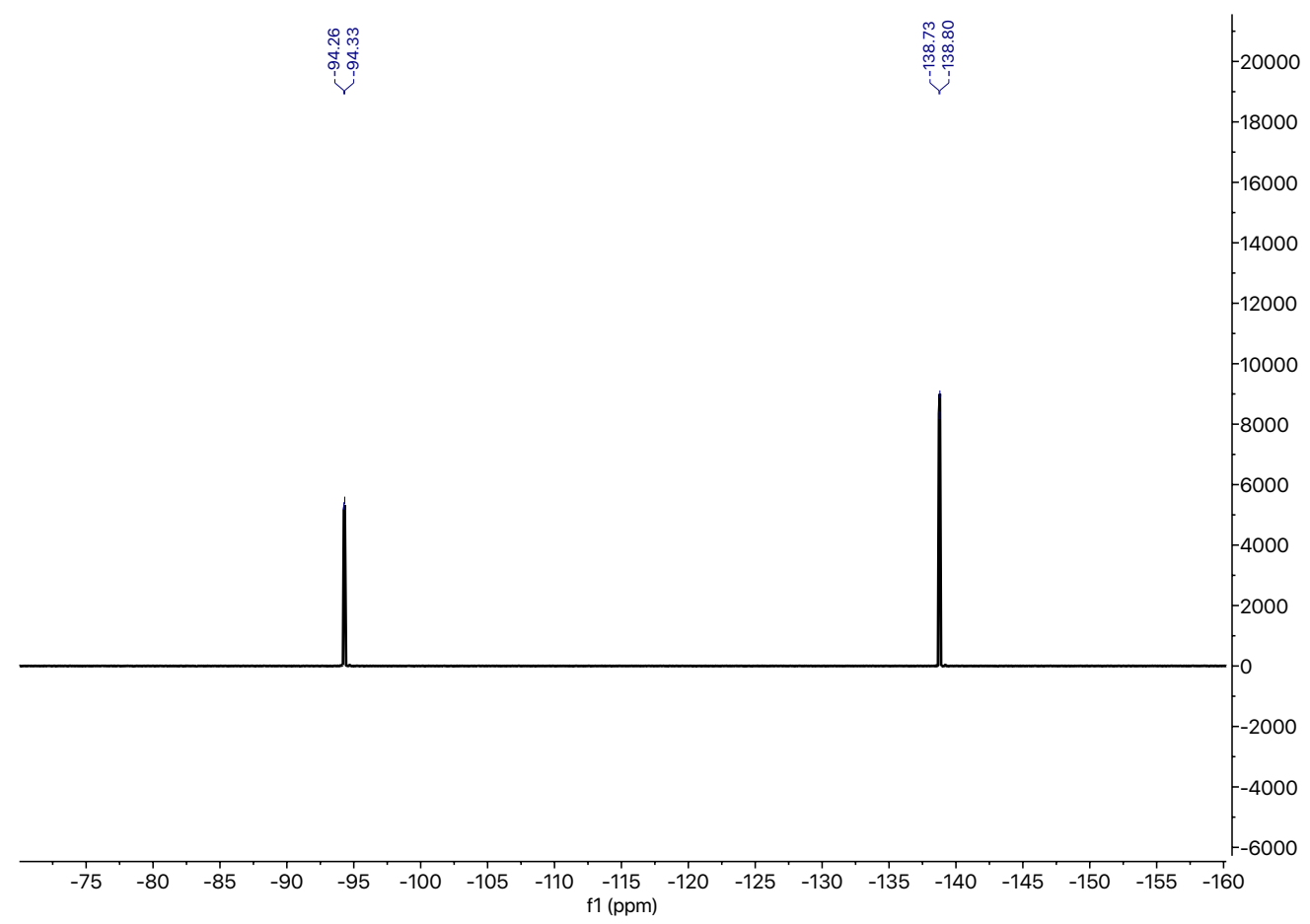

Figure S32. ${ }^{19}$ F NMR spectrum (376 MHz, 298K, DMSO) of $\mathbf{S 1}$

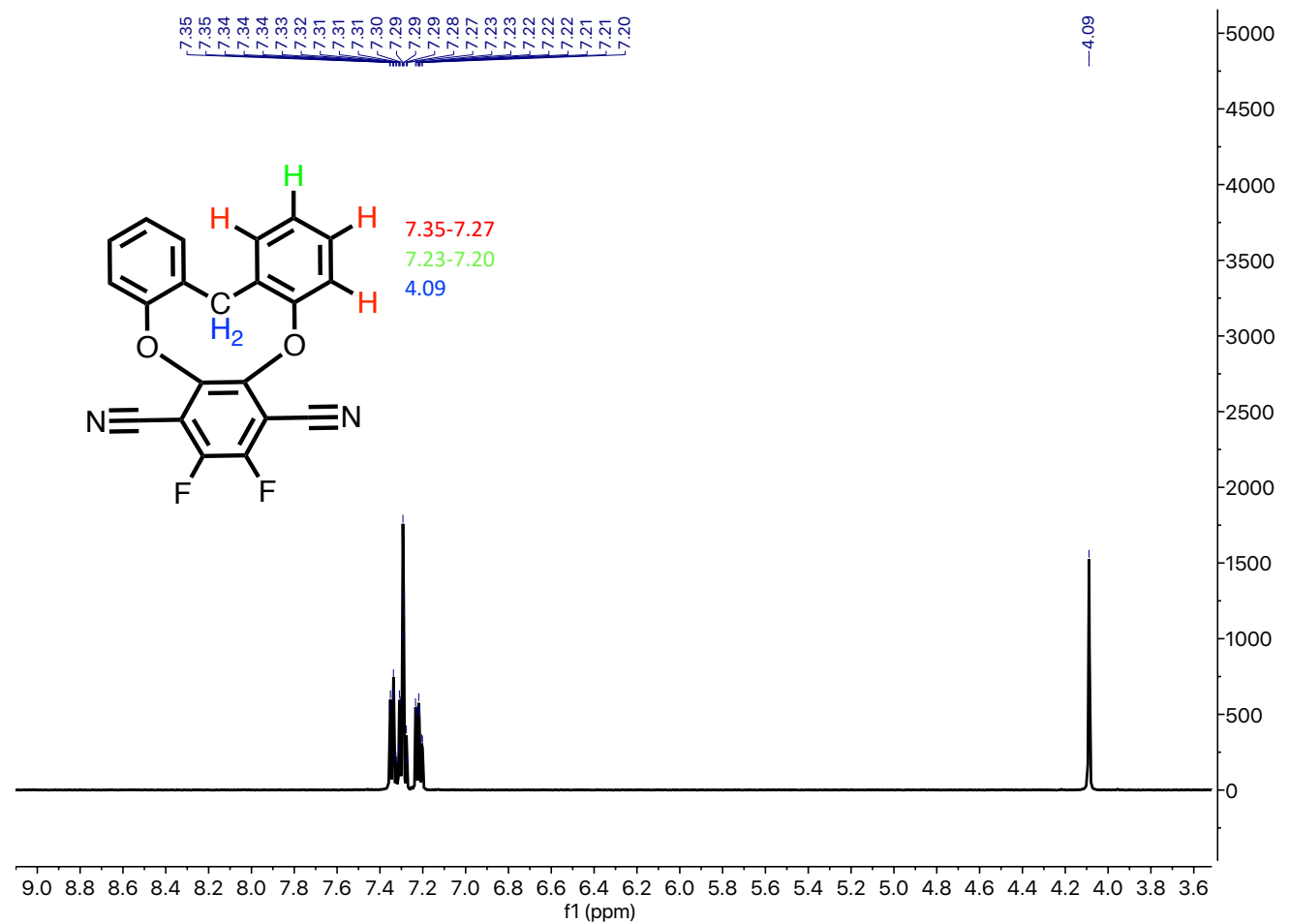

Figure S33. ${ }^{1} \mathrm{H}$ NMR spectrum (500 MHz, 298K, DMSO) of $\mathbf{S 2}$ 


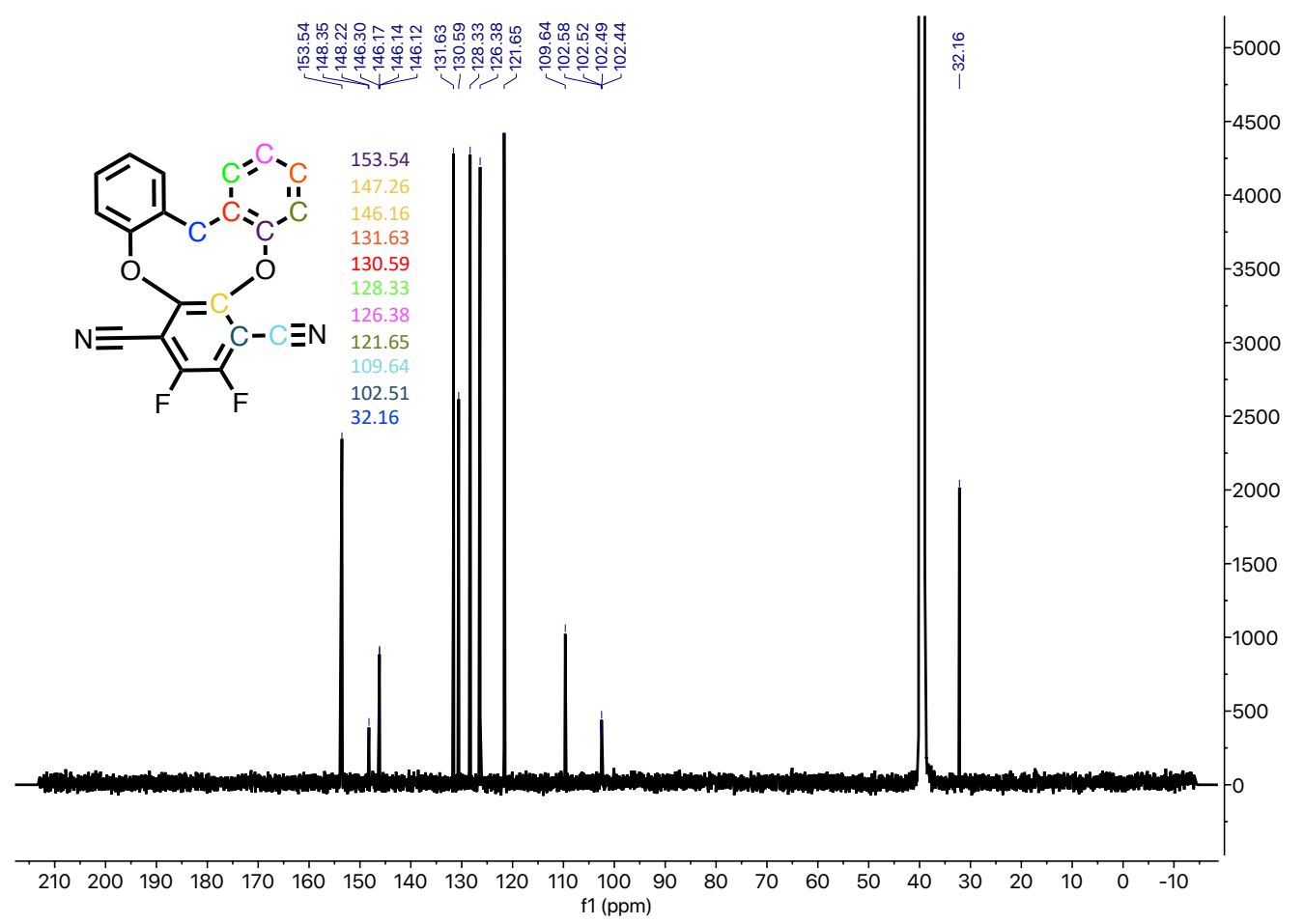

Figure S34. ${ }^{13} \mathrm{C}$ NMR spectrum (126 MHz, 298K, DMSO) of $\mathbf{S 2}$

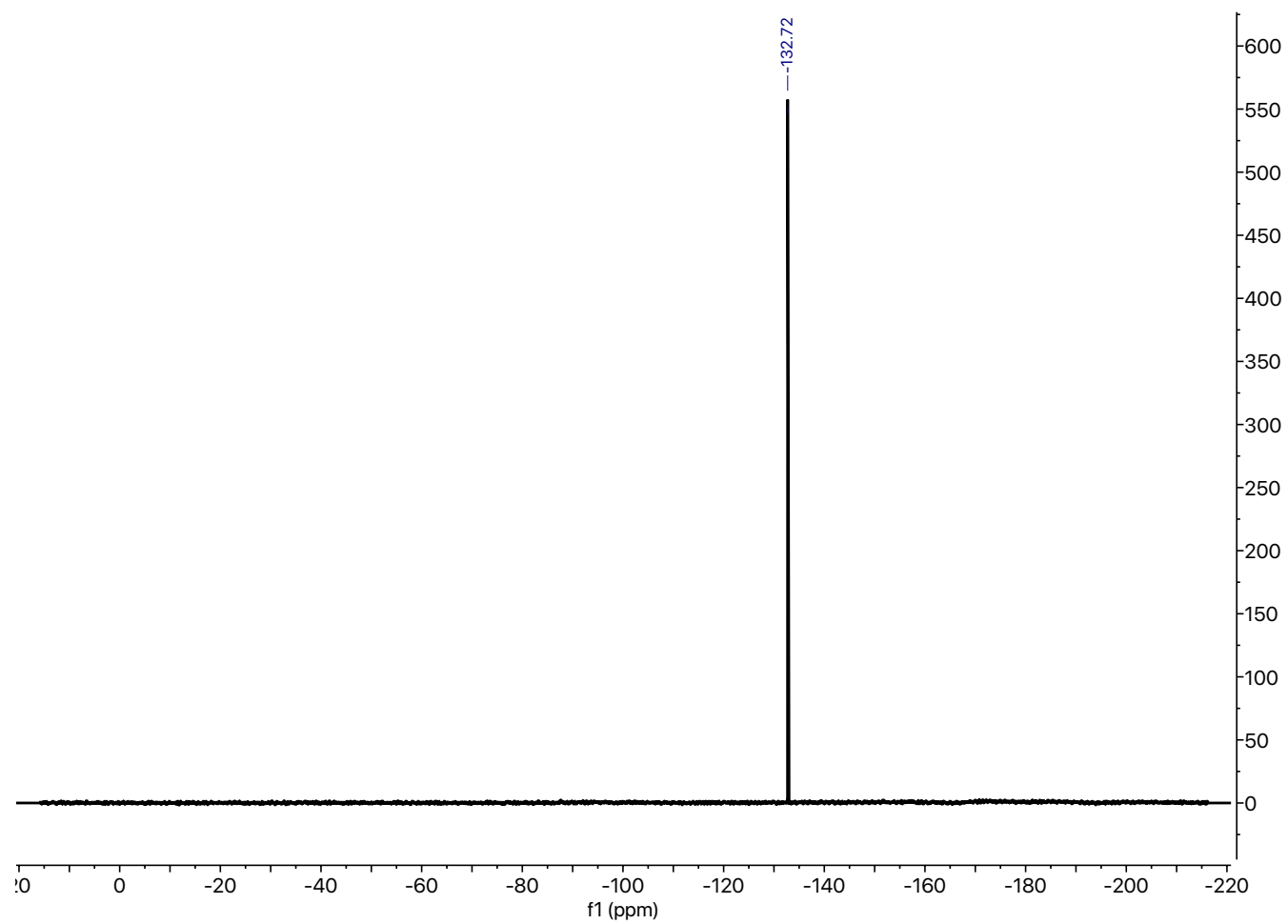

Figure S35. ${ }^{19}$ F NMR spectrum (470 MHz, 298K, DMSO) of S2 
K. Infrared Spectra

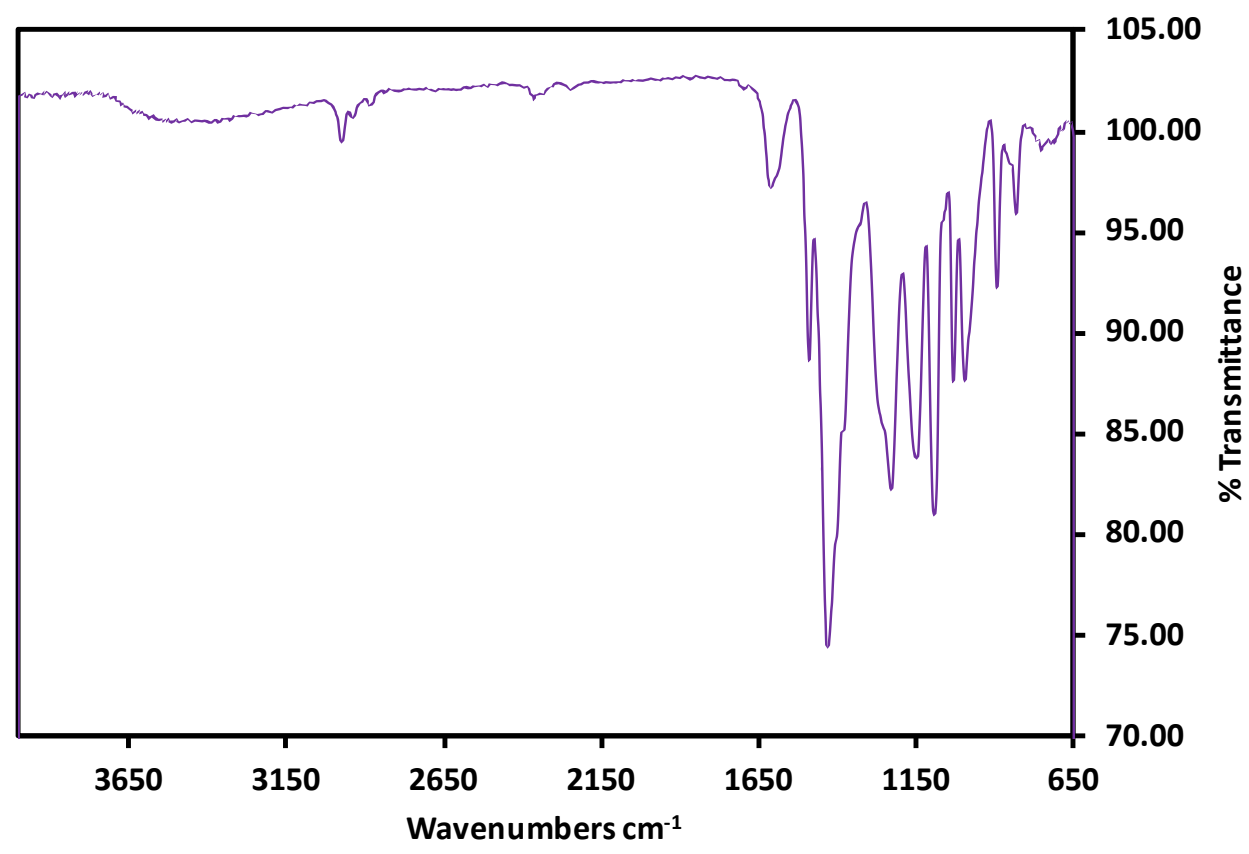

Figure S36. Infrared spectrum of 2

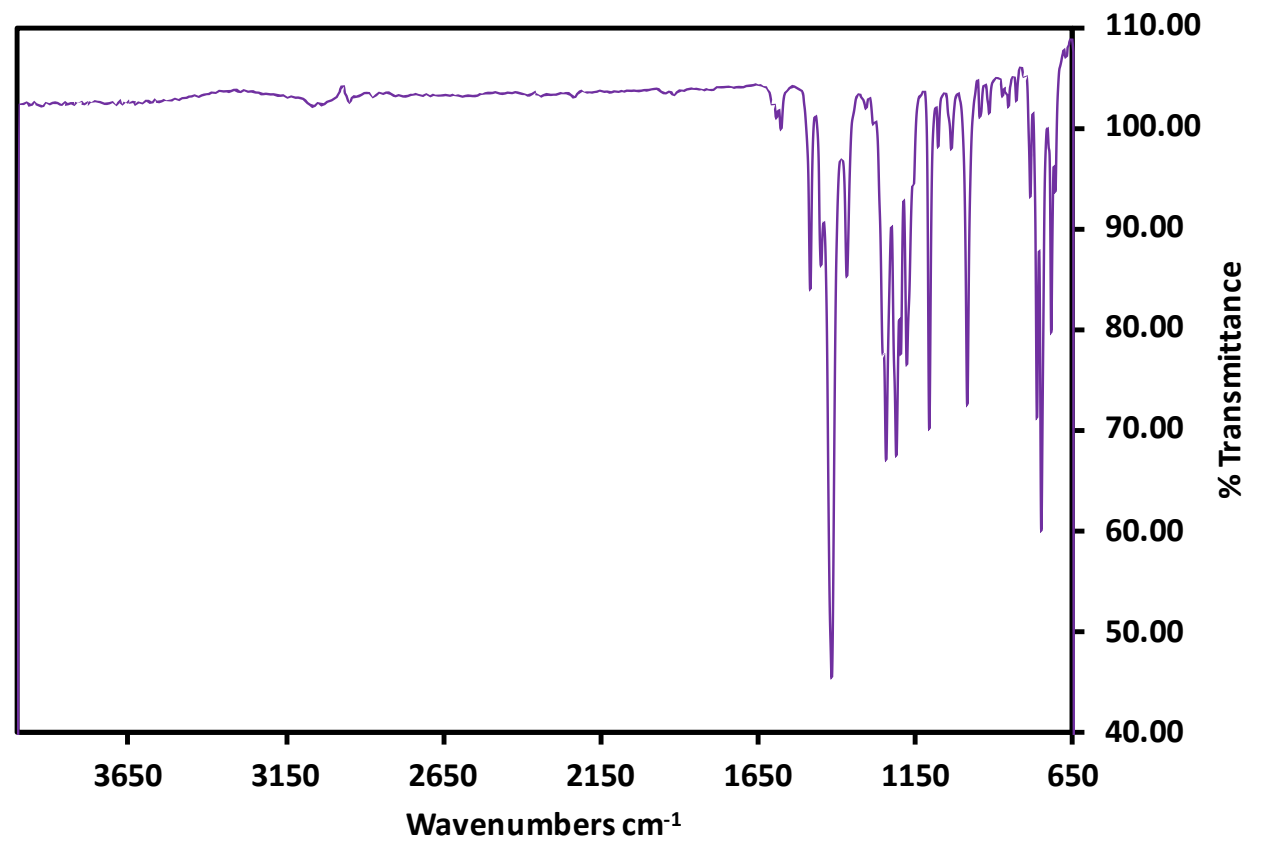

Figure S37. Infrared spectrum of 4 


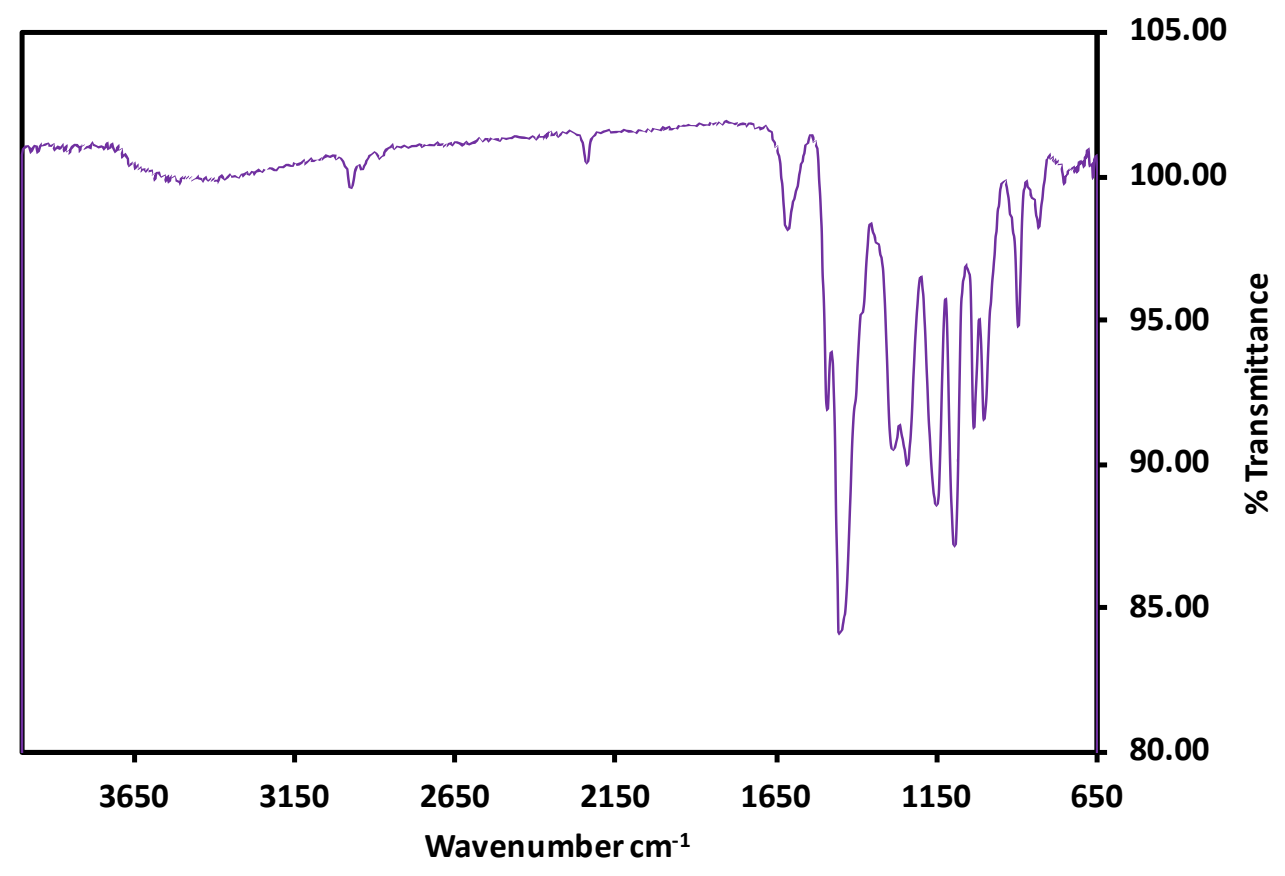

Figure S38. Infrared spectrum of 3

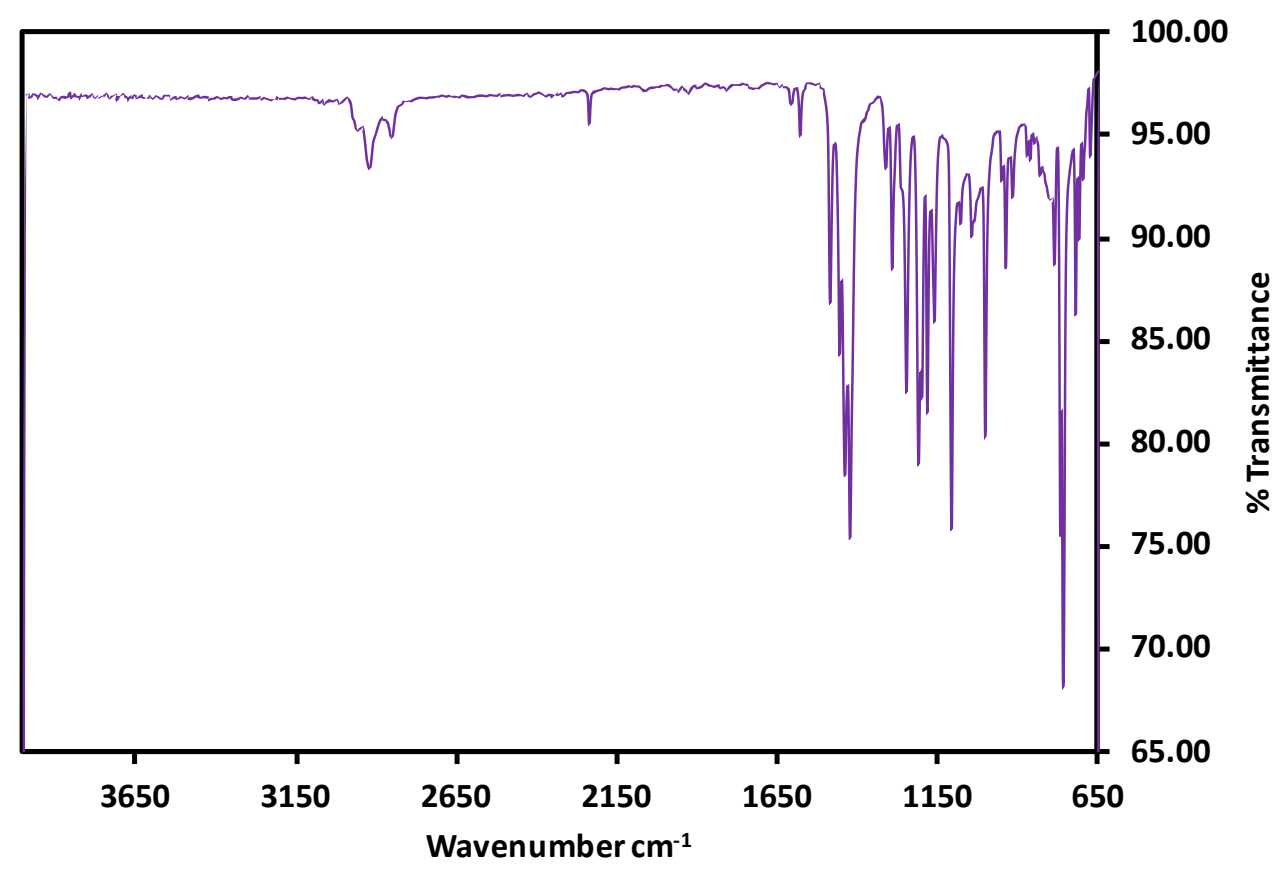

Figure S39. Infrared spectrum of 5 


\section{References}

(1) Fu, R.; Hernández-Maldonado, A. J. Boosting Sensitivity and Suppressing Artifacts via Multi-Acquisition in Direct Polarization NMR Experiments with Small Flip-Angle Pulses. J. Magn. Reson. 2018, 293, 34-40. https://doi.org/10.1016/j.jmr.2018.05.015. 